\title{
Fluorides for the prevention of early tooth decay (demineralised white lesions) during fixed brace treatment (Review)
}

\author{
Benson PE, Parkin N, Dyer F, Millett DT, Furness S, Germain P
}

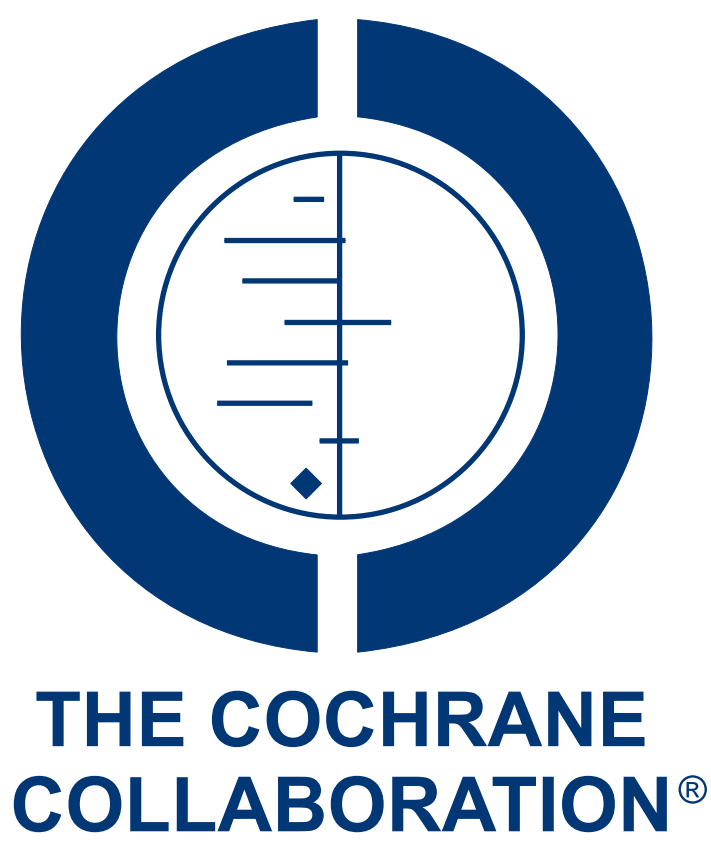

This is a reprint of a Cochrane review, prepared and maintained by The Cochrane Collaboration and published in The Cochrane Library 2013, Issue 12

http://www.thecochranelibrary.com

\section{WILEY}

Fluorides for the prevention of early tooth decay (demineralised white lesions) during fixed brace treatment (Review)

Copyright $\odot 2013$ The Cochrane Collaboration. Published by John Wiley \& Sons, Ltd. 
TABLE OF CONTENTS

HEADER

ABSTRACT

PLAIN LANGUAGE SUMMARY

SUMMARY OF FINDINGS FOR THE MAIN COMPARISON

BACKGROUND

OBJECTIVES

METHODS

Figure 1.

RESULTS

DISCUSSION

AUTHORS' CONCLUSIONS

ACKNOWLEDGEMENTS

REFERENCES

CHARACTERISTICS OF STUDIES

DATA AND ANALYSES.

Analysis 1.1. Comparison 1 Fluoride varnish versus placebo varnish, Outcome 1 Number of participants with new DWLs.

Analysis 2.1. Comparison 2 Amine fluoride/stannous fluoride toothpaste/mouthrinse combination versus sodium fluoride toothpaste/mouthrinse combination, Outcome 1 White spot index.

Analysis 2.2. Comparison 2 Amine fluoride/stannous fluoride toothpaste/mouthrinse combination versus sodium fluoride toothpaste/mouthrinse combination, Outcome 2 Visible plaque index.

Analysis 2.3. Comparison 2 Amine fluoride/stannous fluoride toothpaste/mouthrinse combination versus sodium fluoride toothpaste/mouthrinse combination, Outcome 3 Gingival bleeding index.

Analysis 3.1. Comparison 3 Intraoral fluoride-releasing glass bead device versus mouthrinse-only control, Outcome 1

Number of participants with new DWLs. . . . . . . . . . . . . . . . . . . . . . . . . . . . .

APPENDICES . . . . . . . . . . . . . . . . . . . . . . . . . . . . . . . . . . . . 34

WHAT'S NEW . . . . . . . . . . . . . . . . . . . . . . . . . . . . . . . . . . . . . . 36

CONTRIBUTIONS OF AUTHORS . . . . . . . . . . . . . . . . . . . . . . . . . . . . . . . . . . . . . . 36

DECLARATIONS OF INTEREST . . . . . . . . . . . . . . . . . . . . . . . . . . . . . . . . . . 36

SOURCES OF SUPPORT . . . . . . . . . . . . . . . . . . . . . . . . . . . . . . . . . . . 37

DIFFERENCES BETWEEN PROTOCOL AND REVIEW . . . . . . . . . . . . . . . . . . . . . . 37

INDEX TERMS . . . . . . . . . . . . . . . . . . . . . . . . . . . . . . . . . . . . . . . . . . . . .

Fluorides for the prevention of early tooth decay (demineralised white lesions) during fixed brace treatment (Review)

Copyright $\odot 2013$ The Cochrane Collaboration. Published by John Wiley \& Sons, Ltd. 


\title{
[Intervention Review] \\ Fluorides for the prevention of early tooth decay (demineralised white lesions) during fixed brace treatment
}

\author{
Philip E Benson ${ }^{1}$, Nicola Parkin ${ }^{1}$, Fiona Dyer ${ }^{1}$, Declan T Millett ${ }^{2}$, Susan Furness ${ }^{3}$, Peter Germain ${ }^{4}$ \\ ${ }^{1}$ Academic Unit of Oral Health and Development, School of Clinical Dentistry, University of Sheffield, Sheffield, UK. ${ }^{2}$ Oral Health \\ and Development, Cork University Dental School and Hospital, Cork, Ireland. ${ }^{3}$ Cochrane Oral Health Group, School of Dentistry, \\ The University of Manchester, Manchester, UK. ${ }^{4}$ Department of Orthodontics, Newcastle Dental Hospital, Newcastle upon Tyne, \\ UK
}

Contact address: Philip E Benson, Academic Unit of Oral Health and Development, School of Clinical Dentistry, University of Sheffield, Claremont Crescent, Sheffield, S10 2TA, UK. p.benson@sheffield.ac.uk.

Editorial group: Cochrane Oral Health Group.

Publication status and date: New search for studies and content updated (conclusions changed), published in Issue 12, 2013.

Review content assessed as up-to-date: 31 January 2013.

Citation: Benson PE, Parkin N, Dyer F, Millett DT, Furness S, Germain P. Fluorides for the prevention of early tooth decay (demineralised white lesions) during fixed brace treatment. Cochrane Database of Systematic Reviews 2013, Issue 12. Art. No.: CD003809. DOI: $10.1002 / 14651858 . C D 003809 . p u b 3$.

Copyright (C) 2013 The Cochrane Collaboration. Published by John Wiley \& Sons, Ltd.

\begin{abstract}
A B S T R A C T
Background

Demineralised white lesions (DWLs) can appear on teeth during fixed brace treatment because of early decay around the brackets that attach the braces to the teeth. Fluoride is effective in reducing decay in susceptible individuals in the general population. Individuals receiving orthodontic treatment may be prescribed various forms of fluoride treatment. This review compares the effects of various forms of fluoride used during orthodontic treatment on the development of DWLs. This is an update of a Cochrane review first published in 2004 .
\end{abstract}

Objectives

The primary objective of this review was to evaluate the effects of fluoride in reducing the incidence of DWLs on the teeth during orthodontic treatment.

The secondary objectives were to examine the effectiveness of different modes of fluoride delivery in reducing the incidence of DWLs, as well as the size of lesions. Participant-assessed outcomes, such as perception of DWLs, and oral health-related quality of life data were to be included, as would reports of adverse effects.

\section{Search methods}

We searched the Cochrane Oral Health Group's Trials Register (to 31 January 2013); the Cochrane Central Register of Controlled Trials (CENTRAL) (The Cochrane Library 2012, Issue 12); MEDLINE via OVID (1946 to 31 January 2013); and EMBASE via OVID (1980 to 31 January 2013).

\section{Selection criteria}

We included trials if they met the following criteria: (1) parallel-group randomised clinical trials comparing the use of a fluoridecontaining product versus placebo, no treatment or a different type of fluoride treatment, in which (2) the outcome of enamel demineralisation was assessed at the start and at the end of orthodontic treatment.

Fluorides for the prevention of early tooth decay (demineralised white lesions) during fixed brace treatment (Review)

Copyright @ 2013 The Cochrane Collaboration. Published by John Wiley \& Sons, Ltd. 


\section{Data collection and analysis}

At least two review authors independently, in duplicate, conducted risk of bias assessments and extracted data. Authors of trials were contacted to obtain missing data or to ask for clarification of aspects of trial methodology. The Cochrane Collaboration's statistical guidelines were followed.

\section{Main results}

For the 2013 update of this review, three changes were made to the protocol regarding inclusion criteria. Fourteen studies included in the previous version of the review were excluded from this update for the following reasons: five previously included studies were quasirandomised, a further five were split-mouth studies, three measured outcomes on extracted teeth only and in one, the same fluoride intervention was used in each intervention group of the study.

Three studies and 458 participants were included in this updated review. One study was assessed at low risk of bias for all domains, in one study the risk of bias was unclear and in the remaining study, the risk of bias was high.

One placebo-controlled study of fluoride varnish applied every six weeks (253 participants, low risk of bias), provided moderate-quality evidence of an almost 70\% reduction in DWLs (risk ratio (RR) $0.31,95 \%$ confidence interval (CI) 0.21 to $0.44, \mathrm{P}$ value $<0.001$ ). This finding is considered to provide moderate-quality evidence for this intervention because it has not yet been replicated by further studies in orthodontic participants.

One study compared two different formulations of fluoride toothpaste and mouthrinse prescribed for participants undergoing orthodontic treatment (97 participants, unclear risk of bias) and found no difference between an amine fluoride and stannous fluoride toothpaste/mouthrinse combination and a sodium fluoride toothpaste/mouthrinse combination for the outcomes of white spot index, visible plaque index and gingival bleeding index.

One small study (37 participants) compared the use of an intraoral fluoride-releasing glass bead device attached to the brace versus a daily fluoride mouthrinse. The study was assessed at high risk of bias because a substantial number of participants were lost to followup, and compliance with use of the mouthrinse was not measured.

Neither secondary outcomes of this review nor adverse effects of interventions were reported in any of the included studies.

\section{Authors' conclusions}

This review found some moderate evidence that fluoride varnish applied every six weeks at the time of orthodontic review during treatment is effective, but this finding is based on a single study. Further adequately powered, double-blind, randomised controlled trials are required to determine the best means of preventing DWLs in patients undergoing orthodontic treatment and the most accurate means of assessing compliance with treatment and possible adverse effects. Future studies should follow up participants beyond the end of orthodontic treatment to determine the effect of DWLs on participant satisfaction with treatment.

\section{PLAIN LANGUAGE SUMMARY}

\section{Fluorides for the prevention of early tooth decay (demineralised white lesions) during fixed brace treatment}

\section{Review question}

Ugly white marks sometimes appear on the teeth during orthodontic (brace) treatment. These are caused by early tooth decay and usually occur with fixed (or glued-on 'train track') braces when the teeth are not cleaned properly.

We know that fluoride in toothpaste helps to prevent dental decay; therefore, extra fluoride provided to people wearing braces should protect them from these marks. This review, produced by the Cochrane Oral Health Group, examines the evidence for this in existing research. The aim of this review is to assess the effectiveness of fluorides in preventing early tooth decay during orthodontic (brace) treatment and to determine the best way to do this.

\section{Background}

Early tooth decay around the brackets that attach braces to the teeth can cause white or brown marks (demineralised white lesions (DWLs)) to appear on teeth during fixed brace treatment. Build-up of dental plaque around these brackets is associated with increased risk of rapid demineralisation of the enamel of teeth. Demineralisation is an early, but reversible, stage in the development of tooth

Fluorides for the prevention of early tooth decay (demineralised white lesions) during fixed brace treatment (Review) 
decay. Wearing of fixed braces may be associated with pain, and both the brace and the pain make toothbrushing more difficult, which in turn means that it is harder to prevent the build-up of plaque. People often wear braces for 18 months or longer, and there is a risk that tooth decay will damage the teeth, requiring restorations and fillings to be done.

Fluoride is effective in reducing tooth decay in people who are at risk of developing it. Individuals receiving orthodontic treatment may be prescribed various forms of fluoride treatment. It is important to consider how the fluoride is to be applied and whether children and adolescents (receiving fixed brace treatment) are likely to be willing and able to regularly apply by themselves the amounts needed to prevent early tooth decay.

\section{Study characteristics}

The evidence on which this review is based was up-to-date as of 31 January 2013. Three studies with 458 participants were included in this updated review. Participants were undergoing orthodontic treatment with fixed braces, and DWLs were assessed on teeth remaining in the mouth at the end of orthodontic treatment.

The different ways of applying fluoride that were assessed included:

1. topical fluorides, for example, fluoride-containing varnish, mouthrinse, gel or toothpaste;

2. fluoride-releasing devices attached to the braces; and

3. control group approaches - individuals did not receive additional fluoride as described, or they received a placebo or a different form of fluoride.

\section{Key results}

One study showed that when the dentist paints fluoride-containing varnish around the teeth and brace every time it is adjusted, the risk of developing white marks is reduced by nearly $70 \%$; however, further well-designed trials are required to confirm this finding.

The rest of the evidence is weak, and more studies are needed to show the best way of delivering extra fluoride to people wearing braces. Adverse effects or harms of interventions were not reported in any of the included studies.

\section{Quality of the evidence}

The quality of the evidence found is moderate in the case of one well-designed study and weak in the remaining studies. Recommendations state that further well-conducted research should be conducted in this area. 


\section{SUMMARY OF FINDINGSFOR THE MAINCOMPARISON [Explanation]}

\section{Fluoride varnish versus placebo varnish for the prevention of demineralised white lesions on teeth during fixed brace treatment}

Patient or population: Participants undergoing orthodontic treatment with fixed appliances

Settings: Orthodontic practice

Intervention: Fluoride varnish

Comparison: Placebo varnish

\begin{tabular}{|c|c|c|c|c|c|c|}
\hline \multirow[t]{3}{*}{ Outcomes } & \multicolumn{2}{|c|}{ Illustrative comparative risks* $(95 \%$ Cl) } & \multirow{3}{*}{$\begin{array}{l}\text { Relative effect } \\
(95 \% \mathrm{CI})\end{array}$} & \multirow{3}{*}{$\begin{array}{l}\text { No of participants } \\
\text { (studies) }\end{array}$} & \multirow{3}{*}{$\begin{array}{l}\text { Quality of the evidence } \\
\text { (GRADE) }\end{array}$} & \multirow[t]{3}{*}{ Comments } \\
\hline & Assumed risk & Corresponding risk & & & & \\
\hline & Placebo varnish & Fluoride varnish & & & & \\
\hline \multirow{2}{*}{$\begin{array}{l}\text { Number of patients } \\
\text { with new demineralised } \\
\text { white lesions }\end{array}$} & Study population & & \multirow{2}{*}{$\begin{array}{l}\text { RR } \mathbf{0 . 3 1} \\
(0.21 \text { to } 0.44)\end{array}$} & \multirow{2}{*}{$\begin{array}{l}253 \\
\text { (1 study) }\end{array}$} & \multirow{2}{*}{$\begin{array}{l}\oplus \oplus \oplus \bigcirc \\
\text { moderate }^{1}\end{array}$} & \\
\hline & 640 per 1000 & $\begin{array}{l}198 \text { per } 1000 \\
\text { (134 to } 282)\end{array}$ & & & & \\
\hline
\end{tabular}

${ }^{\star}$ The basis for the assumed risk (e.g. the median control group risk across studies) is provided in footnotes. The corresponding risk (and its $95 \%$ confidence interval) is based on the assumed risk in the comparison group and the relative effect of the intervention (and its $95 \% \mathrm{Cl}$ ).

Cl: confidence interval; RR: risk ratio.

GRADE Working Group grades of evidence.

High quality: Further research is very unlikely to change our confidence in the estimate of effect.

Moderate quality: Further research is likely to have an important impact on our confidence in the estimate of effect and may change the estimate.

Low quality: Further research is very likely to have an important impact on our confidence in the estimate of effect and is likely to change the estimate.

Very low quality: We are very uncertain about the estimate.

${ }^{1}$ A single study with 253 participants evaluated this outcome. Risk of bias was assessed as low. However, this finding should be

interpreted with caution until the study has been replicated. 


\section{B A C K G R O U N D}

\section{Description of the condition}

During orthodontic treatment with fixed appliances, brackets are attached to the teeth to hold the wires that provide the forces required to straighten the teeth. One of the adverse effects of fixed braces is that dental plaque collects around the attachments, leading to accumulation of the types of bacteria that cause dental disease (Naranjo 2006). Build-up of dental plaque around orthodontic brackets is associated with increased risk of demineralised white lesions (DWLs), which can be visible within six months (Tufekci 2011). Demineralisation is an early, but reversible, stage in the development of dental decay (caries). Cariogenic bacteria present in the dental plaque transform sugar in the diet into organic acids, which start to damage the tooth enamel. Effective removal of plaque will prevent DWLs from occurring; however, the presence of orthodontic appliances in the mouth and associated dental pain may make it more difficult for individuals to adequately clean their teeth and braces. DWLs developing on the buccal surfaces of teeth during orthodontic treatment can become a significant problem over the course of treatment, which may last for 18 months or longer, resulting in a poor appearance of the teeth following straightening (Maxfield 2012). In severe cases, caries can develop, requiring restoration (filling); this may be both painful and costly. A recent study by Enaia and colleagues (Enaia 2011) using clinical photographs of the teeth taken before and after fixed brace treatment found that the prevalence of DWLs was 32\% in participants before treatment; however, this proportion rose to $74 \%$ after treatment. Most of the DWLs were minor, but a significant minority of participants (10\%) had cavities in their teeth, which may have required a filling. Although DWLs tend to fade with time as they heal, Ogaard 1989 found that, even five years after treatment, orthodontic participants had a significantly higher incidence of DWLs than a control group of participants who did not undergo orthodontic treatment.

\section{Description of the intervention}

Orthodontists are keen to prevent the development of DWLs so their patients may have the best possible outcome following orthodontic treatment - well-aligned caries-free teeth. Fluoride is important in the prevention of dental decay (ten Cate 2013). Marinho and colleagues (Marinho 2003) found a definite reduction in caries in children and adolescents who performed regular supervised rinsing with a fluoride mouthwash. It has also been shown that fluoride may reduce the number of DWLs that develop during brace treatment. When orthodontic participants used a mouthrinse, Geiger et al (Geiger 1992) found a 30\% reduction in the number of participants and a $25 \%$ reduction in the incidence of teeth affected by DWLs. Many orthodontists recommend the use of a daily fluoride mouthrinse throughout brace treatment to prevent DWLs (Kerbusch 2012).

Several methods (in addition to fluoridated toothpaste) are used to deliver fluoride to teeth in patients during orthodontic treatment. These include the following.

- Topical fluorides (e.g. mouthrinse, gel, varnish).

- Fluoride-releasing materials (e.g. glues used to bond the brackets onto the teeth and orthodontic elastics that are impregnated with fluoride).

- Dietary fluoride supplementation (e.g. fluoridated milk).

\section{How the intervention might work}

Fluoride present in the mouth reduces caries development via three mechanisms: inhibition of the demineralisation of dental enamel, enhancement of the remineralisation of dental enamel producing a remineralised layer that is resistant to acid attack and inhibition of the bacterial enzymes that produce the acid (Lynch 2006; ten Cate 2013).

Most children undergoing orthodontic treatment will be exposed to some fluoride - low concentrations in the water supply, higher concentrations from fluoridated dentifrices (toothpaste), or both. Use of additional topical fluorides and/or fluoride sources designed to deliver additional fluoride to the at-risk area near orthodontic brackets are likely to reduce the risk of DWL development. Topical fluorides include fluoride mouthrinses, varnishes, gels, dentifrices and dietary sources (e.g. fluoridated milk). Specific orthodontic sources of fluoride include bracket adhesives and orthodontic elastic bands (elastomeric ligatures), which slowly release fluoride into the mouth. All of these fluoride sources release fluoride into saliva that is distributed throughout the mouth.

\section{Why it is important to do this review}

Several systematic reviews have investigated the effects of delivering fluoride in various modes on dental caries in children and adolescents (Marinho 2003; Marinho 2003a; Marinho 2003b; Marinho 2004); however, these systematic reviews did not examine the effects of fluoride on participants wearing fixed orthodontic braces.

Some orthodontists routinely recommend to their patients the use of fluoride mouthrinses. However, clear evidence is lacking regarding the optimum concentration of fluoride in mouthrinses, the optimum frequency of mouthrinse use and the effects of mouthrinses and other topical fluorides over the duration of orthodontic treatment.

This is an update of a Cochrane review first published in 2004 to summarise evidence of the effects of the use of any topical fluoride on the prevention of demineralised white lesions in patients undergoing orthodontic treatment. 


\section{O B J E C T I V E S}

The primary objective of this review was to evaluate the effects of fluoride in reducing the incidence of demineralised white lesions (DWLs) on the teeth during orthodontic treatment.

The secondary objectives were to examine the effectiveness of different modes of fluoride delivery in reducing the incidence of DWLs, as well as the size of lesions. Participant-assessed outcomes, such as perception of DWLs, and oral health-related quality of life data were to be included, as would reports of adverse effects.

\section{METHODS}

\section{Criteria for considering studies for this review}

\section{Types of studies}

We included randomised controlled trials (RCTs) in which topical fluoride was delivered by any method to prevent enamel demineralised white lesion (DWL) formation during orthodontic treatment with fixed braces. As topical fluorides are distributed throughout the mouth by saliva, the use of a split-mouth study design to evaluate these interventions is inappropriate. (Split-mouth studies included in the previous version of this review found no difference between teeth with fluoridated bracket adhesives and those without, supporting the view that this design is inappropriate for evaluating topical fluorides.) We have excluded split-mouth studies from the 2013 update of this review.

\section{Types of participants}

Included were participants of any age who were undergoing orthodontic treatment with fixed braces in situations where DWLs were assessed on teeth remaining in the mouth at the end of orthodontic treatment (at debonding, immediately after the active fixed brace is removed). We excluded studies that evaluated demineralisation of extracted teeth (ex vivo).

\section{Types of interventions}

- Topical fluoride in the form of toothpaste, mouthrinse, gel, varnish or dietary sources at any dose, frequency, duration or method of administration, and with any of the following active agents/ingredients: $\mathrm{NaF}$ (sodium fluoride), SMFP (sodium monofluorophosphate), SnF (stannous fluoride), APF (acidulated phosphate fluoride) and amine F (amine fluoride).

- Materials containing fluoride that is released during treatment, including fluoride-releasing composite resin-bonding materials, glass ionomer cements, compomers and resin- modified glass ionomers for bonding or banding, slow-release fluoride devices and fluoride-releasing elastomeric ligatures.

- The control group comprises individuals not subjected to the fluoride intervention but instead treated with a placebo, such as a non-fluoride toothpaste and mouthrinse, or given no intervention. Studies involving a control subjected to an alternative fluoride intervention were also included.

\section{Types of outcome measures}

\section{Primary outcomes}

- The outcome measure was the presence/absence of new DWLs by participant. This can be assessed directly from the participant or preferably from start and finish photographs or fluorescent images of the teeth (immediately after the active fixed brace is removed). If the number of DWLs was not recorded at the start of treatment, the outcome was the presence or absence of DWLs at the end of the orthodontic treatment period, again assessed directly from the participant or indirectly from photographs or fluorescent images of the teeth.

\section{Secondary outcomes}

- Differences in size and severity of DWLs between experimental and control groups.

- Any quantitative assessment of enamel mineral loss, such as fluorescent light techniques or microradiography, used with in situ caries models (Benson 2010).

- Any participant-assessed outcomes, such as perception of DWLs and oral health-related quality of life data.

- Adverse effects.

\section{Search methods for identification of studies}

For the identification of studies included or considered for this review, detailed search strategies were developed for each database searched. No restrictions were placed on the language of publication when searching the electronic databases. Searches were originally done in July 2003 and were undertaken again in May 2012 and January 2013 for this update of the review.

\section{Electronic searches}

We searched the following electronic databases.

- The Cochrane Oral Health Group's Trials Register (to 31 January 2013) (Appendix 1).

- The Cochrane Central Register of Controlled Trials (CENTRAL) (The Cochrane Library 2012, Issue 12) (Appendix 2).

- MEDLINE via OVID (1946 to 31 January 2013)

(Appendix 3). 
- EMBASE via OVID (1980 to 31 January 2013) (Appendix

4).

\section{Searching other resources}

The bibliographies of identified RCTs and review articles were checked for additional studies.

\section{Unpublished studies}

The US National Institutes of Health Trials Register was searched in June 2013 for ongoing studies. Personal contacts were used to identify unpublished RCTs.

\section{Handsearching}

The following journals were identified as important to be handsearched for this review.

- American Journal of Orthodontics and Dentofacial

Orthopedics

- The Angle Orthodontist

- European Journal of Orthodontics

- [British] Journal of Orthodontics

- Clinical Orthodontics and Research

- Journal of Dental Research

- Journal of Dentistry

- Caries Research

- Journal of Clinical Orthodontics.

These journals are included in the Cochrane Worldwide Handsearching Programme. See the Cochrane Masterlist for details of issues searched to date. Only handsearching done as part of this programme and uploaded to CENTRAL was included.

\section{Data collection and analysis}

\section{Selection of studies}

Two review authors independently examined the title, keywords and abstract of reports identified through electronic searching for evidence of three criteria.

- A randomised clinical trial of participants undergoing orthodontic treatment.

- A trial comparing the use of a fluoride-containing product versus no use or use of a non-fluoride control.

- A trial that assessed enamel demineralisation at the start and at the end of orthodontic treatment.

For studies that appeared to meet the inclusion criteria, or for which data in the title and abstract were insufficient to allow a clear decision, the full report was obtained. Disagreements were resolved by discussion.
No language restrictions were applied. Translations of foreign language articles were produced by contacts within the Cochrane Oral Health Group.

\section{Data extraction and management}

Data were extracted by two review authors independently, in duplicate, using specially designed data extraction forms. The data extraction forms were piloted on several papers and were modified as required before use. Any disagreement was discussed, and a third review author was consulted when necessary. All authors were contacted for clarification of missing information. Data from studies in which the reporting was incomplete were not included in the analysis until the corresponding author of the study had supplied adequate clarification. If agreement could not be reached, data were excluded from the review. All studies that met the inclusion criteria underwent validity assessment and data extraction. Studies rejected at this or subsequent stages were recorded, along with reasons for exclusion, in the 'Characteristics of excluded studies' table.

For each trial, the following data were recorded.

- Year of publication and country of origin.

- Study design.

- Unit of randomisation.

- Details of participants, including demographic characteristics and criteria for inclusion.

- Details of types of interventions (method of delivery of fluoride, dose, duration of use).

- Details of outcomes reported (number, size and severity of white spot lesions), including method of assessment and mean duration of the study.

\section{Assessment of risk of bias in included studies}

This assessment was conducted by using the recommended approach for assessing risk of bias in studies included in Cochrane reviews (Higgins 2011). We used the two-part tool to address the six specific domains (namely, sequence generation, allocation concealment, blinding, incomplete outcome data, selective outcome reporting and other bias). Each domain includes one or more specific entries in a 'Risk of bias' table. Within each entry, the first part of the tool involves describing what was reported to have happened in the study. The second part of the tool involves assigning a judgement relating to the risk of bias for that entry: either low risk, unclear risk or high risk.

The domains of sequence generation, allocation concealment, incomplete outcome data and selective outcome reporting are addressed in the tool by a single entry for each study. For blinding, two entries were used because assessments need to be made separately for (1) participants and operators/orthodontists and (2) outcome assessors. When the operator/orthodontist assessed the outcome of the trial, this was noted. The final domain ('other sources of bias') was assessed as a single entry for studies as a whole. 
The risk of bias assessment was undertaken independently and in duplicate by two review authors as part of the data extraction process. Disagreements were resolved by discussion.

After taking into account additional information provided by the authors of the trials, review authors grouped studies into the following categories.

\begin{tabular}{|c|c|c|c|}
\hline Risk of bias & Interpretation & Within a study & Across studies \\
\hline Low risk of bias & $\begin{array}{l}\text { Plausible bias unlikely to seriously } \\
\text { alter the results }\end{array}$ & Low risk of bias for all key domains & $\begin{array}{l}\text { Most information comes from } \\
\text { studies at low risk of bias }\end{array}$ \\
\hline Unclear risk of bias & $\begin{array}{l}\text { Plausible bias that raises some } \\
\text { doubt about the results }\end{array}$ & $\begin{array}{l}\text { Unclear risk of bias for one or more } \\
\text { key domains }\end{array}$ & $\begin{array}{l}\text { Most information comes from } \\
\text { studies at low or unclear risk of bias }\end{array}$ \\
\hline High risk of bias & $\begin{array}{l}\text { Plausible bias that seriously weak- } \\
\text { ens confidence in the results }\end{array}$ & $\begin{array}{l}\text { High risk of bias for one or more } \\
\text { key domains }\end{array}$ & $\begin{array}{l}\text { The proportion of information } \\
\text { from studies at high risk of bias is } \\
\text { sufficient to affect the interpreta- } \\
\text { tion of results }\end{array}$ \\
\hline
\end{tabular}

A risk of bias table was completed for each included study. Results were also presented graphically (Figure 1). 
Figure I. Risk of bias summary: review authors' judgements about each risk of bias item for each included study.

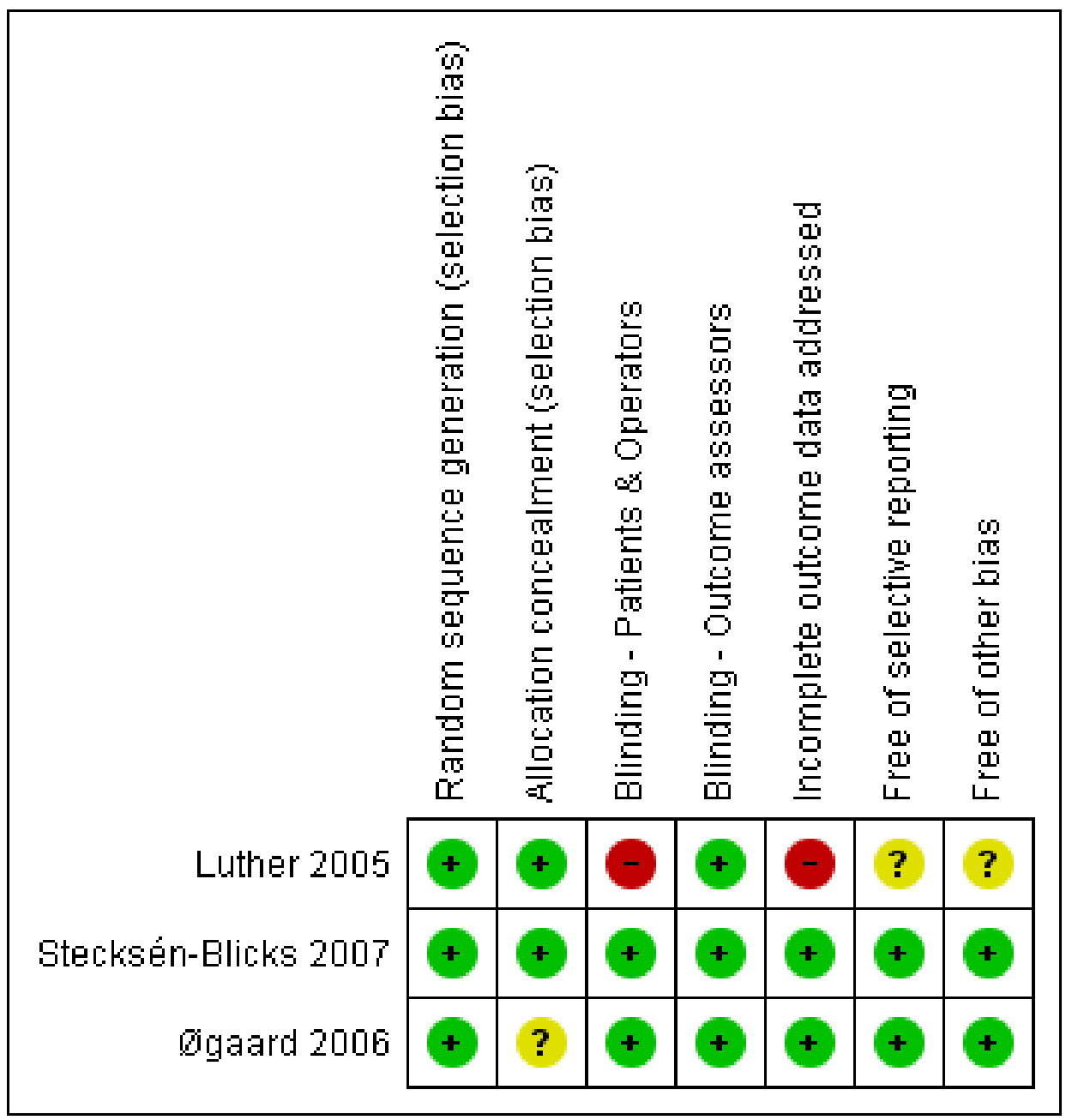

\section{Measures of treatment effect}

For dichotomous outcomes, the estimate of effect of an intervention was expressed as risk ratios (RRs) together with $95 \%$ confidence intervals (CIs). For continuous outcomes, we estimated mean differences (MDs) and 95\% CIs.

\section{Unit of analysis issues}

In parallel-group trials in which participants are randomly assigned to intervention or to control and a single outcome measure per participant is reported, the analysis is straightforward. When individuals are randomly assigned to treatment, each individual has a number of teeth exposed to the intervention or to the con- trol. When the outcome is reported per number of teeth, the data should be adjusted for clustering within the mouth of each individual to avoid unit of analysis errors. If it is unclear from the reports of included trials whether clustering has been considered, authors were contacted to clarify how this dependence has been accounted for in the analysis.

\section{Dealing with missing data}

When data were not available in the printed report, or when data were unclear, we contacted the corresponding author of the study to obtain the missing data. The analysis generally includes only available data (ignoring missing data); however, we would have used methods of estimating missing standard deviations as pro- 
vided in Section 7.7.3 of the Cochrane Handbook for Systematic Reviews of Interventions (Higgins 2011), if appropriate. Otherwise, we did not undertake any imputations or use statistical methods to allow for missing data.

\section{Assessment of heterogeneity}

Pooling of data and meta-analysis were carried out only if sufficient similarities were noted between studies in types of participants, interventions and outcomes, including the time of the outcome measurement. If any trials were pooled, the significance of discrepancies in the estimates of treatment effects from the different trials was to be assessed by using Cochran's test for heterogeneity, by which heterogeneity was considered significant if $\mathrm{P}$ value $<0.1$ (Higgins 2011).

The $\mathrm{I}^{2}$ statistic, which describes the percentage total variation across studies that is due to heterogeneity rather than to chance, was used to quantify heterogeneity, with $\mathrm{I}^{2}$ greater than $50 \%$ considered to show substantial heterogeneity (Higgins 2011: Section 9.5.2).

\section{Assessment of reporting biases}

Only a proportion of research projects conducted are ultimately published in an indexed journal and become easily identifiable for inclusion in systematic reviews. Reporting biases arise when reporting of research findings is influenced by the nature and direction of the findings of the research. We investigated and attempted to minimise in this review potential reporting biases, including publication bias, time lag bias, multiple (duplicate) publication bias and language bias.

If more than ten studies were included for one outcome, we would have constructed a funnel plot. Any asymmetry in the funnel plot indicating possible publication bias would have been investigated by statistical analysis using the methods introduced by Egger 1997 (continuous outcome) and Rücker 2008 (dichotomous outcome) (such analysis would have been done in STATA 11.0).

\section{Data synthesis}

A meta-analysis was to be conducted only if studies of similar comparisons reported the same outcome measures. Risk ratios would have been combined for dichotomous data and mean differences for continuous data, using random-effects models, provided more than three studies were included in the meta-analysis.

\section{Subgroup analysis and investigation of heterogeneity}

We planned to investigate clinical heterogeneity by examining the different sources of fluoride. Provided sufficient studies were identified for each intervention and outcome, we planned a priori to conduct subgroup analyses for different sources of fluoride (mouthrinse, gel, varnish dentifrice, bracket adhesive, elastomeric ligature).

\section{Sensitivity analysis}

It was planned to undertake sensitivity analyses to examine the effects of quality assessment items on the assessment of overall estimates of effect.

In addition, the effect on findings of the review of including unpublished literature was to be examined.

\section{Summary of findings table}

A 'Summary of findings' table was developed for the primary outcomes of this review using GRADEProfiler software. The quality of the body of evidence was assessed with reference to the overall risk of bias of the included studies, the directness of the evidence, the inconsistency of the results, the precision of the estimates, the risk of publication bias, the magnitude of the effect and whether evidence of a dose response was found. The quality of the body of evidence for each of the primary outcomes was categorised as high, moderate, low or very low.

\section{R E S U L T S}

\section{Description of studies}

\section{Results of the search}

The original search identified 191 publications, of which 101 were excluded after removal of duplicates and review of the title or abstract. Full-text articles were obtained for the remaining 90. From the 90 full articles, 58 references were assessed as ineligible for inclusion in this review. We contacted 18 study authors concerning 29 references. On the basis of information provided, 15 references were excluded and three were pending further information, leaving 14 trials, involving 613 participants, included in the original version of this review.

For the 2013 update of this review, three changes to the protocol regarding inclusion criteria resulted in the exclusion of all previously included studies. Five previously included quasi-randomised trials were excluded (Banks 2000; Dyer 1982; Hirschfield 1978; Millett 2000; Sonis 1989), five previously included split-mouth studies were excluded (Chung 1998; Czochrowska 1998; Gillgrass 2001; Marcusson 1997; Twetman 1997) and three previously included studies were excluded because outcomes were measured ex vivo on extracted teeth (Gorton 2003; Øgaard 1986; Pascotto 2004). Øgaard 2001 was excluded because investigators compared fluoride versus fluoride plus antiseptic. 
Three additional studies were identified by the updated search (Luther 2005; Øgaard 2006; Stecksén-Blicks 2007), for a total of 458 participants included in the 2013 update of this review. Three ongoing studies were identified (NCT01925924; NCT00268138; NCT01768390).

For details of the studies examined and reasons for inclusion or exclusion, please see Characteristics of included studies and Characteristics of excluded studies tables.

\section{Included studies}

Three parallel-group randomised controlled trials (Luther 2005; Øgaard 2006; Stecksén-Blicks 2007) were included in the update of this review.

\section{Characteristics of the trial participants and setting}

Two of the included studies were conducted in Sweden (Øgaard 2006; Stecksén-Blicks 2007) and one in the United Kingdom (Luther 2005). Two of the studies included adolescent participants with an age range at baseline of 12 to 15 years, and the study by Luther 2005 also included adults up to the age of 45 years. All participants in the included trials were recruited at the start of their orthodontic treatment with fixed appliances, and in all trials, participants were followed until the end of treatment.

\section{Characteristics of the interventions}

One of the included studies was placebo-controlled (StecksénBlicks 2007), and two conducted head-to-head comparisons. We have grouped these trials into three comparisons.

- Fluoride-containing varnish versus non-fluoride-containing placebo varnish (Stecksén-Blicks 2007).

- Amine fluoride and stannous fluoride toothpaste/ mouthrinse combination versus sodium fluoride toothpaste/ mouthrinse combination (Øgaard 2006).

- Intraoral fluoride-releasing glass bead device versus fluoride mouthrinse (Luther 2005).

\section{Characteristics of the outcomes}

One of the studies reported the outcome of new demineralised white lesions (DWLs) in each participant (Stecksén-Blicks 2007), and one study (Luther 2005) planned to report this outcome but actually reported only that no statistically significant difference was observed between the groups. The third study (Øgaard 2006) reported a white spot index.

None of the three included studies reported data for the secondary outcomes of this review: differences in size and severity of DWLs, quantitative assessment of enamel mineral loss, participant perception of DWLs and any measure of oral health-related quality of life, and adverse effects.

\section{Excluded studies}

A total of 57 studies were excluded from this updated review for the following reasons (for details, see the Characteristics of excluded studies table).

- Split-mouth studies (Banks 1997; Buyukyilmaz 1994; Chung 1998; Czochrowska 1998; Demito 2011; Gillgrass 2001; Marcusson 1997; Mattick 2001; Millett 1999; Millett 2000; Mitchell 1992; Shan 2008; Trimpeneers 1996; Turner 1993; Twetman 1997; van der Linden 1998; Vivaldi-Rodrigues 2006).

- Not truly randomised (controlled clinical trials (CCTs)) (Banks 2000; Blanco 1988; Leizer 2010).

- Not randomised controlled trials (RCTs) (Boyles 2007; Dyer 1982; Farhadian 2008; Fricker 1985; Fricker 1987; Gaworski 1999; Geiger 1988; Geiger 1992; Hirschfield 1978; Maijer 1988; Øgaard 1992; Øgaard 1996; Shannon 1978; Shannon 1979; Sonis 1989; Underwood 1989; Wenderoth 1999).

- Outcomes reported on extracted teeth (ex vivo) (Gorton 2003; O’Reilly 1987; Øgaard 1986; Pascotto 2004).

- Outcomes assessed at the end of fluoride treatment, rather than at debonding (Marini 1999; Robertson 2011;

Sköld-Larsson 2013).

- Outcomes assessed some weeks after debonding (Alexander 2000; Boyd 1992; Boyd 1993).

- Abstracts with insufficient information for inclusion and no response from authors (Alwi 1994; Neumann 1976; Salzmann 1976).

- DMFS/DMFT (decayed, missing and filled surfaces/teeth) outcome measures, not DWLs (D’Agostino 1988; Dénes 1988; Dénes 1989; Dénes 1991).

- Fluoride intervention confounded (Øgaard 1997; Øgaard 2001; Ullsfoss 1994).

\section{Risk of bias in included studies}

Overall risk of bias assessments for all included studies are shown in Figure 1. One study (Stecksén-Blicks 2007) was assessed at low risk of bias for all domains, for another study (Øgaard 2006) the overall risk of bias was unclear and the remaining included study (Luther 2005) was assessed at high risk of bias.

\section{Allocation}

Two of the included studies clearly reported the method of sequence generation and clear allocation concealment and were assessed at low risk of selection bias (Luther 2005; Stecksen-Blicks 2007).

One study (Øgaard 2006) reported the method of sequence generation (randomisation table) but did not mention allocation concealment. This study was assessed at unclear risk of selection bias. 


\section{Blinding}

Two studies were considered truly triple-blind (participant, clinician and assessor) (Øgaard 2006; Stecksén-Blicks 2007) because placebos and comparison interventions were identical in appearance to the experimental intervention.

In Luther 2005, participants and clinicians were not blinded, and the resulting risk of performance bias was high; outcome assessors, however, were blinded, so the risk of detection bias was assessed as low.

\section{Incomplete outcome data}

Few postrandomisation exclusions were reported in StecksénBlicks 2007 and Øgaard 2006, and numbers and reasons for exclusion were similar for each group; therefore, the risk of attrition bias was assessed as low. In Luther 2005, the overall rate of postrandomisation exclusions was very high, so this study was assessed at high risk of attrition bias.

\section{Selective reporting}

Both Stecksén-Blicks 2007 and Øgaard 2006 reported all planned outcomes in full and were assessed at low risk of reporting bias. In the report of the study by Luther 2005, some information was missing and the denominators were not stated, so this study was assessed at unclear risk of reporting bias.

\section{Other potential sources of bias}

In two studies (Øgaard 2006; Stecksén-Blicks 2007), no other sources of bias were identified. Luther 2005 was assessed at unclear risk of other bias because of possible differences between the groups in terms of compliance, duration of orthodontic treatment and exposure to topical fluorides.

\section{Effects of interventions}

See: Summary of findings for the main comparison Fluoride varnish versus placebo varnish

\section{Topical fluorides}

The three studies included in this review evaluated different modes of application of topical fluorides.

- Fluoride-containing varnish versus non-fluoride-containing placebo varnish (Stecksén-Blicks 2007).

- Amine fluoride and stannous fluoride toothpaste/ mouthrinse combination versus sodium fluoride toothpaste/ mouthrinse combination (Øgaard 2006).

- Intraoral fluoride-releasing glass bead device versus fluoride mouthrinse (Luther 2005).

\section{Fluoride varnish/paste versus placebo}

The trial by Stecksén-Blicks 2007 compared application of fluoride varnish (Fluor Protector containing 0.1\% fluoride (F) as difluorosilane in a polyurethane varnish base, Ivoclar Vivadent) every six weeks versus a non-fluoride-containing placebo varnish, in a double-blind study assessed as being at low risk of bias. The outcome was new demineralised white lesions (DWLs) identified from clinical photographs taken before and after orthodontic treatment. A reduction of DWLs (almost 70\%) was associated with regular application of fluoride varnish during orthodontic treatment in this study (risk ratio (RR) $0.31,95 \%$ confidence interval (CI) 0.21 to 0.44; Analysis 1.1). No adverse effects were reported. The study result should be interpreted cautiously until further clinical trials confirm this finding.

\section{Different types of fluoride administered in toothpaste and mouthrinse}

Øgaard 2006 compared two different types of fluoride compounds provided as toothpaste (twice daily) and mouthrinse (once daily) and supplied to participants for use during orthodontic treatment. One group received amine fluoride/stannous fluoride toothpaste (Meridol 140 parts per million (ppm) F, pH 4.5) and amine fluoride/stannous fluoride mouthrinse to be used after toothbrushing at bedtime (250 ppm F, pH 4.0). The other group received neutral sodium fluoride toothpaste (1400 ppm, pH 6.7) and a sodium fluoride mouthrinse (250 ppm F, pH 6.3) to be used after brushing at bedtime.

The outcome of new DWLs was reported at the tooth level with no indication of correction for clustering of teeth within the mouth. The mean change in the white spot lesion index from baseline was greater in the sodium fluoride group, suggesting that this compound was less effective than amine fluoride/stannous fluoride (Analysis 2.1). A slightly larger increase in both the visible plaque index and the gingival bleeding index was reported over the duration of treatment in the group exposed to sodium fluoride (Analysis 2.2; Analysis 2.3). However, these differences should be interpreted cautiously until the results can be independently replicated.

\section{Fluoride-releasing intraoral device}

In the study by Luther and colleagues (Luther 2005), the experimental group received a carbonate-based glass bead containing $13.3 \%$ fluoride glass (Telsol (UK) Ltd), which was attached to the orthodontic brace. The control group was requested to use a daily fluoride mouthrinse (Endekay rinse $0.05 \% \mathrm{w} / \mathrm{v} \mathrm{NaF}$, StaffordMiller Ltd). The number and size of new DWLs were determined using computerised image analysis of before and after cross-polarised (to reduce flash reflections) photographic images of six anterior teeth in each participant. Results were available for only 37 participants of the original 70 recruited (53\%) (Analysis 3.1). The glass beads proved to be fragile, and 18 breakages were reported. 


\section{Secondary outcomes}

None of the three included studies reported data for the secondary outcomes of this review: any differences in size and severity of DWLs, quantitative assessment of enamel mineral loss, participant perception of DWLs and any measure of oral health-related quality of life, and adverse effects.

\section{Sensitivity analyses}

Insufficient trials were included in the review for a sensitivity analysis to be undertaken.

\section{Publication bias}

Insufficient trials were included in this review to enable the review authors to investigate publication bias.

\section{DISCUSSION}

\section{Summary of main results}

Moderate-quality evidence from one trial at low risk of bias indicates that fluoride varnish applied every six weeks is associated with a reduction in new demineralised white lesions (DWLs) (Summary of findings for the main comparison).

Evidence is insufficient to show whether amine fluoride and stannous fluoride toothpaste/mouthrinse combination is more or less effective than sodium fluoride toothpaste/mouthrinse combination in preventing DWLs, visible plaque or gingivitis.

Evidence is also insufficient to show whether a reduction in the development of DWLs occurs with the use of an intraoral fluoridereleasing glass bead device.

\section{Overall completeness and applicability of evidence}

The latest update of the review has included only parallel-group trials, in which the individual participant is the unit of randomisation. This was decided upon because of the possibility of cross-contamination between experimental and control teeth in the same mouth, either between upper and lower arches or between sides of the mouth, which might lead to under-estimation of the effectiveness of any fluoride products.

Interventions that rely on the patient for delivery, including fluoride mouthrinse and toothpaste, will work only if they are used regularly. They rely greatly on patient compliance to succeed; however, evidence suggests that compliance with mouthrinsing is poor among orthodontic patients. One study (Geiger 1992) found that only $42 \%$ of participants rinsed with a sodium fluoride mouthrinse at least every other day. Results also showed that those who complied least with fluoride rinsing regimens tended to have more DWLs. It is important to consider the acceptability of interventions to both adolescents and adults with a view toward increasing compliance with recommended dental hygiene practices.

Interventions that are professionally applied and deliver fluoride 'passively', such as fluoride varnish, fluoride-releasing bracket cements and fluoride-releasing elastics, avoid the need for patient compliance. In addition, these materials deliver fluoride close to the bracket, where it is most needed; however, many fluoridated materials release large amounts of fluoride initially, but the level drops rapidly and might not be sufficient to prevent decay over the whole course of orthodontic treatment. Reapplication of fluoride varnish and frequent replacement of fluoride-releasing elastics are likely to be required. In the parallel-group trial of a fluoride varnish intervention included in this review, varnish was reapplied every six weeks at each orthodontic check-up appointment. We found no parallel-group trials of fluoride-releasing cements or elastics that met the inclusion criteria for this review.

An interesting addition, since the initial review was carried out, is the further development of materials that produce a slow and sustained release of fluoride (Luther 2005). This trial was small and at high risk of bias, and evidence was insufficient to reveal whether these devices are more or less effective than a mouthrinse in reducing the development of DWLs. It is possible, that with further refinement, this technique could potentially be effective. Intraoral fluoride-releasing devices should be evaluated by doubleblind parallel-group randomised controlled trials.

When examining the effectiveness of a fluoride product in preventing dental decay, one should consider two aspects: first, whether the fluoride product reduces the number of DWLs appearing during treatment, and second, whether it reduces the severity of DWLs in terms of the size or area of the tooth surface affected, the amount of mineral lost or the depth of decay. Banks et al (Banks 2000) developed the Enamel Decalcification Index, which is an ordinal index that includes an assessment of the area covered. Assessment of the size of the lesion is a useful outcome measure, but none of the studies included in this review reported this outcome.

Ideally the appearance of the tooth should be recorded before and after orthodontic treatment, so that the change in appearance of the tooth is measured (incidence), not just its appearance at the end (prevalence). There are many different causes of white lesions on the teeth, many of which occur during the development of the teeth. It is important that these development lesions, as well as decay that has occurred before the brace is fitted, are excluded from the analysis, hence the need for the images (photographs or fluorescent) taken before treatment. Measurement of both incidence and severity will depend on the method used to record DWLs. Two main methods may be used: visual inspection and clinical images. Both methods are associated with problems. One problem with visual inspection is that the examiner or examiners will require calibration at the start and regular recalibration throughout 
the experimental period to ensure consistency of measurement. The duration of the experiment might be quite long because, as discussed later, the product should ideally be tested over the entire length of orthodontic treatment. This can take between 18 and 30 months - sometimes longer. Another problem with visual recording involves masking of the assessor to the allocated intervention. To reduce bias, the examiner should not know whether the participant has received a fluoride product and this will complicate the way the experiment is run.

Images have the advantage of providing a permanent record of the appearance of the tooth. Assessments can be carried out by several people independently or in groups, whereby a consensus is achieved. The images can be placed in a random order and the judges masked to group allocation. In addition, because the assessment can be performed over a short period of time the problem of examiner drift, whereby an assessor might subtly change his or her assessment over time, is reduced. The challenge of using clinical photographs consists of achieving consistency in lighting and reducing reflections that can mask or mimic DWLs; however, when a careful photographic technique is applied, the advantages of photographs outweigh their potential disadvantages. Several optical and fluorescent methods are available for measuring lesions on the teeth (Angmar-Mansson 1996). These methods require specialised equipment, which would add considerably to the cost of a clinical study, but they provide an objective measurement of the amount of decay in terms of mineral loss or lesion depth or both.

\section{Quality of the evidence}

It is important to note that only one study included in this review was judged to be at low risk of bias, and this assessment was made only after contact with the author resulted in clarification of two issues. Both the design and the reporting of trials of fluorides for preventing DWLs were generally poor, even in the most recent trials published in journals for which the use of CONSORT guidelines has been adopted. In particular, the methods of random allocation, sequence generation and concealment were rarely explained. Few studies provided a flow diagram to show withdrawals and drop-outs.

\section{Potential biases in the review process}

We undertook a sensitive search of several electronic sources, supplemented by searches of references lists. We placed no restriction on language or publication status. The review authors have tried, as far as possible, to identify all possible studies that might meet the inclusion criteria for this review. Study authors have been contacted, and many have replied; however, some were not able to supply the requested information, as their records have been destroyed or lost.
When a product, such as a bonding material, can be applied to single teeth, it is tempting to use an experimental design whereby the material being tested is used in two quadrants of the mouth and the control material is used in the other two quadrants. This is called a split-mouth design. The main advantage of the splitmouth design over a conventional parallel-group study design, in which the two materials are tested in two separate groups of individuals, is that the experimental material is tested in the same mouth, under the same conditions as the control material. In theory, any differences in outcome between the two materials are due only to their properties - not to other factors, such as differences in oral hygiene and diet between participants (with a parallel design) or even differences in oral hygiene and diet over time within the same participants (with a cross-over design).

Unfortunately, when one is examining the ability of fluoride products to reduce decay, it is highly unlikely that the fluoride released will be confined to only the quadrants/teeth in which the experimental material has been placed, and some contamination of the 'untreated' teeth is inevitable. This contamination will reduce the difference in outcomes between treated and untreated teeth. The previous version of this review included split-mouth studies, which failed to show any difference between treated and untreated teeth; this may be due to cross-over contamination between control and experimental sides and may reflect our contention of contamination. For this reason, we have decided to exclude split-mouth studies from this update of our review, and we recognise that changes to the protocol introduce a risk of bias to the review process.

\section{Agreements and disagreements with other studies or reviews}

Three other systematic reviews gathering evidence for the most effective means of preventing caries/demineralisation during fixed orthodontic appliance treatment have been reported in the literature. Derks et al (Derks 2004) examined all preventive measures for preventing demineralisation - not just fluoride products. These review authors had to exclude many published studies as well because of inappropriate research design or poor reporting and were unable to provide firm, evidence-based recommendations as to the prevention of DWLs during fixed orthodontic treatment.

A second systematic review (Chadwick 2005) investigated the effectiveness of topical fluorides used alone in preventing demineralisation during orthodontic treatment. These review authors included seven studies in their review; however, these studies were excluded from our review because the outcomes were not appropriate (DMFT/DMFS), or the participants were not examined immediately after removal of the fixed appliance(s). Although they suggest that according to their outcome measure (preventive fraction), some evidence shows that the addition of a topical fluoride preparation helps in the prevention of demineralisation during fixed orthodontic treatment, this conclusion must be viewed with caution, because these review authors were not able to calculate 
confidence intervals. We support their request that researchers design and report their studies using standard outcomes, so that in the future, data may be pooled and overall recommendations on preventive measures may be provided.

Rogers et al (Rogers 2010) included 10 studies in their systematic review investigating the effectiveness of fluoride-containing bonding adhesives used in orthodontics to prevent demineralisation. Five of these studies were excluded from our review because they were not randomised, and a further three studies were excluded because data in the report were insufficient, and the study authors, when contacted, were unable to provide requested data. Rogers' conclusions are consistent with ours with regard to the design of trials and the quality of reporting and statistical analyses.

\section{AUTHORS'CONCLUSIONS}

\section{Implications for practice}

Moderate quality-evidence from one well-designed clinical trial suggests that six-weekly, professional application of a varnish containing a high concentration of fluoride reduces the incidence of demineralised white lesions (DWLs) during orthodontic treatment; however, further well-designed studies are required to confirm this finding.

Evidence is insufficient for review authors to recommend the use of intraoral fluoride-releasing devices. Such interventions, provided they sustain the release of fluoride, have the potential to be effective, as they reduce the requirement for patient compliance. Fluoride mouthrinses, in addition to fluoride toothpastes, have been found to be effective in reducing caries in non-orthodontic patients, but no direct evidence from this review indicates that these interventions are effective in patients with fixed orthodontic appliances. It is likely that fluorides that do not require patient compliance will be more effective in preventing DWLs.

\section{Implications for research}

More evidence is required before the most effective way of delivering fluoride to the orthodontic patient can be determined. In particular, fluoride delivery methods that do not require patient compliance should be studied. Adequately powered, double-blind, placebo-controlled trials, with appropriate randomisation, allocation concealment and masking of outcome assessment, are needed. However, a placebo-only group may be considered unethical. The use of factorial designs, whereby two or more experimental interventions are evaluated simultaneously allowing for the evaluation of possible interaction between the interventions, can be evaluated separately. Researchers should, however, be aware that increasing the number of arms in a trial will substantially increase the number of participants required to demonstrate a statistical difference between interventions.
Another weakness of many studies was that they were undertaken over a relatively short period of orthodontic treatment. Short-term studies tend to overestimate the effectiveness of an intervention, particularly if it is a fluoride product, which releases high levels of fluoride initially, or if the intervention requires sustained patient co-operation. The effectiveness of products over the full duration of orthodontic treatment should be assessed. The influence of confounders, such as diet, fluoridated water supplies and age of the participant, as well as other outcomes, including participantreported data, should be included in trial designs.

The use of images to record the condition of the tooth before and after treatment should be encouraged. Images provide a permanent record, allowing before and after comparisons of the incidence and severity of DWLs with proper assessor blinding, error analysis and consensus measures. To provide a reproducible method of recording DWLs using photographs, a standard technique is required, with thought given to reduction of flash reflection, magnification and drying of the teeth. Optical and fluorescent methods of providing a quantitative measurement of mineral loss should be encouraged if funding allows. Studies ideally should assess participant-centred outcomes, including the effect of DWLs on quality of life, particularly six months or a year after treatment.

\section{ACKNOW LEDGEMENTS}

Thanks are due to Helen Worthington (Cochrane Oral Health Group) for invaluable help with the statistics and to Sylvia Bickley and Anne Littlewood, Trials Search Co-ordinators for the Cochrane Oral Health Group, for carrying out the searches for the review.

Our thanks to Helen Worthington for her assistance with the 2013 update of this review.

For help with the translations of foreign papers, our thanks go to Regina Mitezki (German), Luisa Fernandez Mauleffinch (Spanish) and Dr Mikako Hayashi (Japanese).

We would also like to thank the following investigators who replied to our requests for additional information about their trials: PA Banks (Fairfield General Hospital, Burnley), AJ Borislow (Albert Einstein Medical Center), JP Fricker (Westmead Centre Dental Clinical School), G Pauw (University of Ghent), JDB Featherstone (University of California at San Fransisco), CR Mattick (University of Newcastle upon Tyne), L Mitchell (St Luke's Hospital, Bradford), B Øgaard (University of Oslo), RC Pascotto (State University of Maringa), M Persson (Umeå University), AL Sonis (Harvard School of Dental Medicine), C Stecksen-Blicks, PJ Turner (University of Birmingham) and S Twetman (Umeå University).

We acknowledge the contribution of Suzy Vine, who assessed the eligibility of trials, extracted data and assessed the quality of the trials in the original version of this review. 
For their help as referees of the original review, we express our thanks to Jayne Harrison, Sylvia Bickley, Helen Worthington, Anne-Marie Glenny, Lee Hooper, Richard Ellwood, Sue Higham and Aubrey Sheiham. Our thanks to the referees for the 2013 update: Scott Deacon, Ruth Floate, Anne Littlewood, Phil Riley and Helen Worthington.

\section{R E F E R E N C E S}

\section{References to studies included in this review}

Luther 2005 \{published and unpublished data\}

Luther F, Tobin M, Robertson AJ, Toumba KJ. Fluoridereleasing glass beads in orthodontic treatment to reduce decay: a randomized, controlled clinical trial. World Journal of Orthodontics Supplement 2005;6(5):166-7.

Stecksén-Blicks 2007 \{published and unpublished data\} Stecksén-Blicks C, Renfors G, Oscarson ND, Bergstrand F, Twetman S. Caries-preventive effectiveness of fluoride varnish: a randomized controlled trial in adolescents with fixed orthodontic appliances. Caries Research 2007;41(6): 455-9.

Øgaard 2006 \{published and unpublished data\} Øgaard B, Alm AA, Larsson E, Adolfsson U. A prospective, randomized clinical study on the effects of an amine fluoride/stannous fluoride toothpaste/mouthrinse on plaque, gingivitis and initial caries lesion development in orthodontic patients. European Journal of Orthodontics 2006;28(1):8-12.

\section{References to studies excluded from this review}

Alexander 2000 \{published data only\}

Alexander SA, Ripa LW. Effects of self-applied topical fluoride preparations in orthodontic patients. The Angle Orthodontist 2000;70(6):424-30.

Alwi 1994 \{published data only\}

Alwi NBH, Creanor SL. The influence of fluoride-releasing composites on the development of white-spot lesions near orthodontic brackets: an in vivo investigation (Research Reports 1993: Abstract). British Journal of Orthodontics 1994;21(1):118.

Banks 1997 \{published data only\} Banks PA, Burn A, O'Brien K. A clinical evaluation of the effectiveness of including fluoride into an orthodontic bonding adhesive. European Journal of Orthodontics 1997; 19(4):391-5. [MEDLINE: 9308260]

Banks 2000 \{published data only\}

Banks PA, Chadwick SM, Asher-McDade C, Wright JL. Fluoride-releasing elastomerics-a prospective controlled clinical trial. European Journal of Orthodontics 2000;22(4): 401-7. [MEDLINE: 11029829]

Blanco 1988 \{published data only\} Blanco Parra R. Evaluation of the presence of white spots following orthodontic treatment. Revista Iberoamericana de Ortodoncia 1988;8(1):31-8.
Boyd 1992 \{published data only\}

Boyd RL. Two-year longitudinal study of a peroxidefluoride rinse on decalcification in adolescent orthodontic patients. Journal of Clinical Dentistry 1992;3(3):83-7. [MEDLINE: 1449617]

Boyd 1993 \{published data only\}

Boyd RL. Comparison of three self-applied topical fluoride preparations for control of decalcification. The Angle Orthodontist 1993;63(1):25-30. [MEDLINE: 8507027]

Boyles 2007 \{published data only\}

Bagby MD, Boyles GAC, Martin C, Kao E, Ngan P. Effects of fluoride varnishes on enamel decalcification around orthodontic appliances. American Association of Dental Research poster abstract; 2008 March 31-April 5; Dallas, TX.

* Boyles GA. Effects of Fluoride Varnishes and Adhesives on Bond Strength and Preventing Enamel Decalcification Around Orthodontic Appliances: an In Vitro and In Vivo Study [MSc (Orthodontics)]. Morgantown, West Virginia: West Virginia University, 2007.

Buyukyilmaz 1994 \{published data only\}

* Buyukyilmaz T, Tangugsorn V, Ogaard B, Arends J,

Ruben J, Rolla G. The effect of titanium tetrafluoride (TiF4) application around orthodontic brackets. American Journal of Orthodontics and Dentofacial Orthopedics 1994; 105(3):293-6. [MEDLINE: 8135216]

Buyukyilmaz T, Tangugsorn V, Ogaard B, Arends J, Ruben J, Rolla G. The effect of titanium tetrafluoride (TiF4) application around orthodontic brackets. European Journal of Orthodontics 1993;15(4):334.

Chung 1998 \{published and unpublished data\} Chung CK, Millett DT, Creanor SL. Cariostatic ability of resin-modified glass ionomer cements for orthodontic bonding. European Journal of Orthodontics 1996;18(5):513. * Chung CK, Millett DT, Creanor SL, Gilmour WH, Foye RH. Fluoride release and cariostatic ability of a compomer and a resin-modified glass ionomer cement used for orthodontic bonding. Journal of Dentistry 1998;26(5-6): 533-8.

Czochrowska 1998 \{published data only\} Czochrowska E, Ogaard B, Duschner H, Ruben J, Arends J. Cariostatic effect of a light-cured, resin-reinforced glassionomer for bonding orthodontic brackets in vivo. A combined study using microradiography and confocal laser 
scanning microscopy. Journal of Orofacial Orthopedics 1998; 59(5):265-73. [MEDLINE: 9800441]

D'Agostino 1988 \{published data only\}

D'Agostino RB, Cancro LP, Fischman S. Effects of anticaries dentifrices on orthodontic subjects. The Compendium of Continuing Education in Dentistry 1988;11:S384-9.

Demito 2011 \{published and unpublished data\} Demito CF, Rodrigues GV, Ramos AL, Bowman SJ. Efficacy of a fluoride varnish in preventing white-spot lesions as measured with laser fluorescence. Journal of Clinical Orthodontics 2011;45(1):25-9.

Dénes 1988 \{published data only\}

Dénes J, Gábris K. Results of a 3-year Elmex program during orthodontic treatment with fixed appliances. $Z W R$ 1988;97(10):863-8.

Dénes 1989 \{published data only\} Dénes J, Domokos G, Gábris K, Juhász G, Nagy B, Radóczi $\mathrm{B}$, et al.Results of the use of amine-fluoride preparations in orthodontic practice. Fogorvosi Szemle 1989;82(9):257-61.

Dénes 1991 \{published data only\}

Dénes J, Gábris K. Results of a 3-year oral hygiene programme, including amine fluoride products, in patients treated with fixed orthodontic appliances. European Journal of Orthodontics 1991;13(2):129-33.

Dyer 1982 \{published data only\}

Dyer JR, Shannon IL. MFP versus stannous fluoride mouthrinses for prevention of decalcification in orthodontic patients. American Society of Dentistry for Children Journal of Dentistry for Children 1982;49(1):19-21. [MEDLINE: 6948831]

Farhadian 2008 \{published and unpublished data\} Farhadian N, Miresmaeili A, Eslami B, Mehrabi S. Effect of fluoride varnish on enamel demineralization around brackets: an in-vivo study. American Journal of Orthodontics and Dentofacial Orthopedics 2008;133(4 Supplement): S95-8.

Fricker 1985 \{published data only\}

Fricker JP, McLachlan MD. Clinical studies of glass ionomer cements. Part I-A twelve month clinical study comparing zinc phosphate cement to glass ionomer. Australian Orthodontic Journal 1985;9(1):179-80.

Fricker 1987 \{published data only\}

Fricker JP, McLachlan MD. Clinical studies on glass ionomer cements. Part 2-A two year clinical study comparing glass ionomer cement with zinc phosphate cement. Australian Orthodontic Journal 1987;10(1):12-4.

Gaworski 1999 \{published data only\}

Gaworski M, Weinstein M, Borislow AJ, Braitman LE. Decalcification and bond failure: a comparison of a glass ionomer and a composite resin bonding system in vivo. American Journal of Orthodontics and Dentofacial Orthopedics 1999;116(5):518-21. [MEDLINE: 10547510]

Geiger 1988 \{published data only\}

Geiger AM, Gorelick L, Gwinnett AJ, Griswold PG. The effect of a fluoride program on white spot formation during orthodontic treatment. American Journal of Orthodontics and Dentofacial Orthopedics 1988;93(1):29-37.

Geiger 1992 \{published data only\}

Geiger AM, Gorelick L, Gwinnett AJ, Benson BJ. Reducing white spot lesions in orthodontic populations with fluoride rinsing. American Journal of Orthodontics and Dentofacial Orthopedics 1992;101(5):403-7.

Gillgrass 2001 \{published and unpublished data\} Gillgrass TJ, Benington PC, Millett DT, Newell J, Gilmour WH. Modified composite or conventional glass ionomer for band cementation? A comparative clinical trial. American Journal of Orthodontics and Dentofacial Orthopedics 2001; 120(1):49-53.

Gorton 2003 \{published data only\} Gorton J, Featherstone JD. In vivo inhibition of demineralization around orthodontic brackets. American Journal of Orthodontics and Dentofacial Orthopedics 2003; 123(1):10-4.

Hirschfield 1978 \{published data only\} Hirschfield RE. Control of decalcification by use of fluoride mouthrinse. American Society of Dentistry for Children Journal of Dentistry for Children 1978;45(6):458-60.

Leizer 2010 \{published and unpublished data\} Leizer C, Weinstein M, Borislow AJ, Braitman LE. Efficacy of a filled-resin sealant in preventing decalcification during orthodontic treatment. American Journal of Orthodontics and Dentofacial Orthopedics 2010;137(6):796-800.

Maijer 1988 \{published data only\}

Maijer R, Smith DC. A comparison between zinc phosphate and glass ionomer cement in orthodontics. American Journal of Orthodontics and Dentofacial Orthopedics 1988;93 (4):273-9. [MEDLINE: 3281438]

Marcusson 1997 \{published and unpublished data\} Marcusson A, Norevall LI, Persson M. White spot reduction when using glass ionomer cement for bonding in orthodontics: a longitudinal and comparative study. European Journal of Orthodontics 1997;19(3):233-42. [MEDLINE: 9239953]

Marini 1999 \{published data only\} Marini I, Pelliccioni GA, Vecchiet F, Alessandri Bonetti G, Checchi L. A retentive system for intra-oral fluoride release during orthodontic treatment. European Journal of Orthodontics 1999;21(6):695-701. [MEDLINE: 10665199]

Mattick 2001 \{published data only (unpublished sought but not used)\} Mattick CR, Mitchell L, Chadwick SM, Wright J. Fluoridereleasing elastomeric modules reduce decalcification: a randomized controlled trial. Journal of Orthodontics 2001; 28(3):217-9.

Millett 1999 \{published data only\} Millett DT, Nunn JH, Welbury RR, Gordon PH. Decalcification in relation to brackets bonded with glass ionomer cement or a resin adhesive. The Angle Orthodontist 1999;69(1):65-70. [MEDLINE: 10022187] 
Millett 2000 \{published and unpublished data\}

Millett DT, McCluskey LA, McAuley F, Creanor SL, Newell J, Love J. A comparative clinical trial of a compomer and a resin adhesive for orthodontic bonding. The Angle Orthodontist 2000;70(3):233-40. [MEDLINE: 10926433]

Mitchell 1992 \{published data only\}

Mitchell L. An investigation into the effect of a fluoride releasing adhesive on the prevalence of enamel surface changes associated with directly bonded orthodontic attachments. British Journal of Orthodontics 1992;19(3): 207-14. [MEDLINE: 1390576]

Neumann 1976 \{published data only\}

Neumann HF. A clinical evaluation of decalcification under orthodontic bands following pretreatment with acidulated phosphate-fluorides and adhesive plastic coatings. (Abstract - Department of Orthodontics, School of Dentistry, Case Western Reserve University, Cleveland, OH, and Fairleigh Dickinson University, Hackensack, NJ, USA). American Journal of Orthodontics 1976;69(6):698-9. [MEDLINE: $\mathrm{CN}-00295371]$

O'Reilly 1987 \{published data only\}

O'Reilly MM, Featherstone JD. Demineralization and remineralization around orthodontic appliances: an in vivo study. American Journal of Orthodontics and Dentofacial Orthopedics 1987;92(1):33-40. [MEDLINE: 3300270]

Pascotto 2004 \{published data only\}

Pascotto RC, Navarro MF, Capelozza Filho L, Cury JA. In vivo effect of a resin-modified glass ionomer cement on enamel demineralization around orthodontic brackets. American Journal of Orthodontics and Dentofacial Orthopedics 2004;125(1):36-41. [MEDLINE: 14718877]

Robertson 2011 \{published data only\}

Johnson D. MI Paste Plus research. American Journal of Orthodontics and Dentofacial Orthopedics 2012;141(5):526. [PUBMED: 22554734]

* Robertson MA, Kau CH, English JD, Lee RP, Powers J, Nguyen JT. MI Paste Plus to prevent demineralization in orthodontic patients: a prospective randomized controlled trial. American Journal of Orthodontics and Dentofacial Orthopedics 2011;140(5):660-8.

Salzmann 1976 \{published data only\}

Salzmann JA. A clinical evaluation of decalcification under orthodontic bands following pretreatment with acidulated phosphate-fluorides and adhesive plastic coatings. (Abstract - Department of Orthodontics, School of Dentistry, Case Western Reserve University, Cleveland, OH, and Fairleigh Dickinson University, Hackensack, NJ, USA). American Journal of Orthodontics 1976;69(6):698.

Shan 2008 \{published and unpublished data\} Shan LH, Cui ZQ, Shen QH, Gao Q, Qiu ZX. Application of light-cure resin-modified glass ionomer cement in orthodontic practice. Journal of Clinical Rehabilitative Tissue Engineering Research 2008;12(6):1149-52.

Shannon 1978 \{published data only\}

Shannon IL, St Clair JR, Pratt GA, West DC. Stannous fluoride versus sodium fluoride in preventive treatment of orthodontic patients. Australian Orthodontic Journal 1978;5 (1):18-24.

Shannon 1979 \{published data only\}

Shannon IL, West DC. Prevention of decalcification in orthodontic patients by daily self-treatment with $0.4 \% \mathrm{SnF} 2$ gel. Pediatric Dentistry 1979;1(2):101-2. [MEDLINE: 298749]

Sköld-Larsson 2013 \{published data only\} Sköld-Larsson K, Sollenius O, Karlsson L, Petersson LG, Twetman S. Effect of fluoridated milk on enamel demineralization adjacent to fixed orthodontic appliances. Acta Odontologica Scandinavica 2013;71(3-4):464-8.

Sonis 1989 \{published data only\}

Sonis AL, Snell W. An evaluation of a fluoride-releasing, visible light-activated bonding system for orthodontic bracket placement. American Journal of Orthodontics and Dentofacial Orthopedics 1989;95(4):306-11.

Trimpeneers 1996 \{published data only\} Trimpeneers LM, Dermaut LR. A clinical evaluation of the effectiveness of a fluoride-releasing visible lightactivated bonding system to reduce demineralization around orthodontic brackets. American Journal of Orthodontics and Dentofacial Orthopedics 1996;110(2):218-22. [MEDLINE: 8760850]

Turner 1993 \{published data only (unpublished sought but not used)\} Turner PJ. The clinical evaluation of a fluoride-containing orthodontic bonding material. Journal of Orthodontics 1993;20(4):307-13.

Twetman 1997 \{published data only\} Twetman S, McWilliam JS, Hallgren A, Oliveby A. Cariostatic effect of glass ionomer retained orthodontic appliances. An in vivo study. Swedish Dental Journal 1997; 21(5):169-75.

Ullsfoss 1994 \{published data only\} Ullsfoss BN, Ogaard B, Arends J, Ruben J, Rolla G, Afseth $J$. Effect of a combined chlorhexidine and $\mathrm{NaF}$ mouthrinse: an in vivo human caries model study. Scandinavian Journal of Dental Research 1994;102(2):109-12. [MEDLINE: 8016555]

Underwood 1989 \{published data only\} Underwood ML, Rawls HR, Zimmerman BF. Clinical evaluation of a fluoride-exchanging resin as an orthodontic adhesive. American Journal of Orthodontics and Dentofacial Orthopedics 1989;96(2):93-9. [MEDLINE: 2527000]

van der Linden 1998 \{published data only\} van der Linden RP, Dermaut LR. White spot formation under orthodontic bands cemented with glass ionomer with or without Fluor Protector. European Journal of Orthodontics 1998;20(3):219-24.

Vivaldi-Rodrigues 2006 \{published and unpublished data\} Vivaldi-Rodrigues G, Demito CF, Bowman SJ, Ramos AL. The effectiveness of a fluoride varnish in preventing development of white spot lesions. World Journal of Orthodontics 2006;7:138-44. 
Wenderoth 1999 \{published data only\}

Wenderoth CJ, Weinstein M, Borislow AJ. Effectiveness of a fluoride-releasing sealant in reducing decalcification during orthodontic treatment. American Journal of Orthodontics and Dentofacial Orthopedics 1999;116(6): 629-34. [MEDLINE: 10587596]

Øgaard 1986 \{published and unpublished data\} Øgaard B, Arends J, Schuthof J, Rolla G, Ekstrand J, Oliveby A. Action of fluoride on initiation of early enamel caries in vivo. A microradiographical investigation. Caries Research 1986;20(3):270-7. [MEDLINE: 3456849]

Øgaard 1992 \{published data only\}

Øgaard B, Rezk-Lega F, Ruben J, Arends J. Cariostatic effect and fluoride release from a visible light-curing adhesive for bonding of orthodontic brackets. American Journal of Orthodontics and Dentofacial Orthopedics 1992;101(4): 303-7. [MEDLINE: 1532684]

Øgaard 1996 \{published data only\} Øgaard B, Duschner H, Ruben J, Arends J. Microradiography and confocal laser scanning microscopy applied to enamel lesions formed in vivo with and without fluoride varnish treatment. European Journal of Oral Sciences 1996;104(4 Pt 1):378-83.

Øgaard 1997 \{published data only\} Øgaard B, Larsson E, Glans R, Henriksson T, Birkhed D. Antimicrobial effect of a chlorhexidine-thymol varnish (Cervitec) in orthodontic patients. A prospective, randomized clinical trial. Journal of Orofacial Orthopedics 1997;58(4):206-13. [MEDLINE: 9282547]

Øgaard 2001 \{published data only\}

Øgaard B, Larsson E, Henriksson T, Birkhed D, Bishara SE. Effects of combined application of antimicrobial and fluoride varnishes in orthodontic patients. American Journal of Orthodontics and Dentofacial Orthopedics 2001;120(1): 28-35.

\section{References to ongoing studies}

\section{NCT00268138 \{published data only\}}

NCT00268138. Phase 4 study prevention of incipient carious lesions (white spot lesions) in patients with fixed orthodontic appliances following the application of Elmex gel. http://clinicaltrials.gov/ct2/show/NCT00268138? term $=$ orthodontic ${ }^{*}$ +and+fluoride\&rank $=6$.

NCT01768390 \{published data only\}

NCT01768390. Caries-preventive effectiveness of a dentifrice containing $5.000 \mathrm{ppm}$ fluoride - a randomized controlled trial in adolescents with fixed orthodontic appliances. http://clinicaltrials.gov/ct2/show/ NCT01768390?term=orthodontic ${ }^{*}$ +and+fluoride\&rank=2.

NCT01925924 \{published and unpublished data\} Benson PE, Millett D. Resin-modified glass ionomer versus composite for orthodontic bonding. A multicentre, randomised, single blinded clinical trial. http:// clinicaltrials.gov/ct2/show/NCT01925924?term= NCT01925924\&rank=1.

\section{Additional references}

\section{Angmar-Mansson 1996}

Angmar-Mansson B, al-Khateeb S, Tranaeus S. Monitoring the caries process. Optical methods for clinical diagnosis and quantification of enamel caries. European Journal of Oral Science 1996;104(4 Pt 2):480-5.

\section{Benson 2010}

Benson PE. Fluoride-containing materials and the prevention of demineralization during orthodontic treatment - which research method should we now use?. Seminars in Orthodontics 2010;16(4):293-301.

\section{Chadwick 2005}

Chadwick BL, Roy J, Knox J, Treasure ET. The effect of topical fluorides on decalcification in patients with fixed orthodontic appliances: a systematic review. American Journal of Orthodontics and Dentofacial Orthopedics 2005; 128(5):601-6.

\section{Derks 2004}

Derks A, Katsaros C, Frencken JE, van't Hof MA, KuijpersJagtman AM. Caries-inhibiting effect of preventive measures during orthodontic treatment with fixed appliances. Caries Research 2004;38(5):413-20.

\section{Enaia 2011}

Enaia M, Bock N, Ruf S. White-spot lesions during multibracket appliance treatment: a challenge for clinical excellence. American Journal of Orthodontics and Dentofacial Orthopedics 2011;140(1):e17-e24.

Higgins 2011

Higgins JPT, Green S (editors). Cochrane Handbook for Systematic Reviews of Interventions Version 5.1.0 (updated March 2011). The Cochrane Collaboration, 2011. Available from www.cochrane-handbook.org.

Kerbusch 2012

Kerbusch AE, Kuijpers-Jagtman AM, Mulder J, Sanden WJ. Methods used for prevention of white spot lesion development during orthodontic treatment with fixed appliances. Acta Odontologica Scandinavica 2012; Vol. 70, issue 6:564-8.

\section{Lynch 2006}

Lynch RJ, Mony U, Ten Cate JM. The effect of fluoride at plaque fluid concentrations on enamel de- and remineralisation at low pH. Caries Research 2006;40(6): 522-9.

\section{Marinho 2003}

Marinho VCC, Higgins JPT, Logan S, Sheiham A. Fluoride mouthrinses for preventing dental caries in children and adolescents. Cochrane Database of Systematic Reviews 2003, Issue 3. [DOI: 10.1002/14651858.CD002284]

\section{Marinho 2003a}

Marinho VCC, Higgins JPT, Logan S, Sheiham A. Fluoride toothpastes for preventing dental caries in children and adolescents. Cochrane Database of Systematic Reviews 2003, Issue 1. [DOI: 10.1002/14651858.CD002278] 
Marinho 2003b

Marinho VCC, Higgins JPT, Logan S, Sheiham A. Topical fluoride (toothpastes, mouthrinses, gels or varnishes) for preventing dental caries in children and adolescents. Cochrane Database of Systematic Reviews 2003, Issue 4. [DOI: 10.1002/14651858.CD002782]

\section{Marinho 2004}

Marinho VCC, Higgins JPT, Sheiham A, Logan S. Combinations of topical fluoride (toothpastes, mouthrinses, gels, varnishes) versus single topical fluoride for preventing dental caries in children and adolescents. Cochrane Database of Systematic Reviews 2009, Issue 1. [DOI: 10.1002/ 14651858.CD002781.pub2]

\section{Maxfield 2012}

Maxfield BJ, Hamdan AM, Tufekci E, Shroff B, Best AM, Lindauer SJ. Development of white spot lesions during orthodontic treatment: perceptions of patients, parents, orthodontists, and general dentists. American Journal of Orthodontics and Dentofacial Orthopedics 2012;141(3): $337-44$.

\section{Naranjo 2006}

Naranjo AA, Triviño ML, Jaramillo A, Betancourth M, Botero JE. Changes in the subgingival microbiota and periodontal parameters before and 3 months after bracket placement. American Journal of Orthodontics and Dentofacial Orthopedics 2006;30(3):275.e17-275.e22.

\section{Ogaard 1989}

Ogaard B. Prevalence of white spot lesions in 19-year-olds: a study on untreated and orthodontically treated persons 5 years after treatment. American Journal of Orthodontics and Dentofacial Orthopedics 1989;96(5):423-7.

\section{Rogers 2010}

Rogers S, Chadwick B, Treasure E. Fluoride-containing orthodontic adhesives and decalcification in patients with fixed appliances: a systematic review. American Journal of Orthodontics and Dentofacial Orthopedics 2010;390:e1-8.

\section{Rücker 2008}

Rücker G, Schwarzer G, Carpenter J. Arcsine test for publication bias in meta-analyses with binary outcomes. Statistics in Medicine 2008;27:746-63.

ten Cate 2013

ten Cate JM. Contemporary perspective on the use of fluoride products in caries prevention. British Dental Journal 2013;214(4):161-7.

\section{Tufekci 2011}

Tufekci E, Dixon JS, Gunsolley JC, Lindauer SJ. Prevalence of white spot lesions during orthodontic treatment with fixed appliances. The Angle Orthodontist 2011;81(2): 206-10.

\section{References to other published versions of this review}

\section{Benson 2002}

Benson PE, Parkin N, Millett DT, Dyer FE, Vine S, Shah A. Fluorides for the prevention of white spots on teeth during fixed brace treatment. Cochrane Database of Systematic Reviews 2002, Issue 3. [DOI: 10.1002/ 14651858.CD003809]

\section{Benson 2004}

Benson PE, Parkin N, Millett DT, Dyer F, Vine S, Shah A. Fluorides for the prevention of white spots on teeth during fixed brace treatment. Cochrane Database of Systematic Reviews 2004, Issue 3. [DOI: 10.1002/ 14651858.CD003809.pub2]

* Indicates the major publication for the study 


\section{CHARACTERISTICS OF STUDIES}

\section{Characteristics of included studies [ordered by study ID]}

Luther 2005

\begin{tabular}{|c|c|}
\hline Methods & $\begin{array}{l}\text { Trial design: 2-arm parallel-group RCT } \\
\text { Unit of randomisation: Participants } \\
\text { Location: Leeds, UK } \\
\text { Number of centres: } 1 \\
\text { Recruitment period: December } 1998 \text { to December } 1999 \\
\text { Funding source: BDA Research Foundation Shirley Glasstone Hughes Memorial Prize } \\
\text { Fund and the Listerine Preventive Care Award }\end{array}$ \\
\hline Participants & $\begin{array}{l}\text { Inclusion criteria: Participants with upper incisors and canines developing and at least } 3 \\
\text { upper permanent incisors and } 1 \text { upper permanent canine erupted, prior to commence- } \\
\text { ment of orthodontic treatment with fixed upper appliances } \\
40 \mathrm{~F} / 28 \mathrm{M} \text { (sic) } \\
\text { Exclusion criteria: Participants with grossly damaged, restored or defective upper per- } \\
\text { manent canines or incisors, participants living in areas with fluoridated water supply, } \\
\text { physically or mentally handicapped individuals, those with comorbidities or requiring } \\
\text { antibiotic cover and pregnant or nursing females } \\
\text { Mean age at baseline, years: } 15.7 \text { (range } 11 \text { to } 45) \\
\text { Number randomised: } 70 \text { ( } 34 \text { F-releasing glass bead and } 36 \mathrm{~F} \text { rinse) } \\
\text { Number evaluated: } 37 \text { (18 F-releasing glass bead and } 19 \mathrm{~F} \text { rinse) }\end{array}$ \\
\hline Interventions & $\begin{array}{l}\text { Comparison: Fluoride-releasing glass beads versus fluoride rinse } \\
\text { Group A }(\mathrm{n}=18) \text { : Fluoride-releasing glass bead (containing } 13.3 \% \mathrm{~F}) \text { attached to ap- } \\
\text { pliance } \\
\text { Group B }(\mathrm{n}=19) \text { : Fluoride rinse (Endekay } 0.05 \% \mathrm{NaF}) \text {. Participants instructed to use } \\
5 \text { drops in } 10 \mathrm{ml} \text { of water and to rinse once daily } \\
\text { Duration of treatment: Approximately } 19 \text { months (recruitment ended December } 1999 \\
\text { final data collection September } 2002)\end{array}$ \\
\hline
\end{tabular}

Outcomes

Before and after cross-polarised images of 6 upper anterior teeth, assessed by a masked individual using image analysis, salivary fluoride levels

Notes

Background exposure to fluoride not reported: Unclear whether participants used fluoride toothpaste

Power calculation reported that 28 participants/group would be needed to show the expected $75 \%$ difference; it was planned to recruit 35 per group to allow for drop-outs Large numbers of participants both withdrawing or dropping out (total 14: 6 control, 8 experimental), as well as insufficient data for analysis (total 19: 11 control, 8 experimental). Null findings should be interpreted with caution, as investigators lost so many in their sample, which means that it is likely that this study lacks statistical power

Risk of bias

Bias

Authors' judgement

Support for judgement

Fluorides for the prevention of early tooth decay (demineralised white lesions) during fixed brace treatment (Review) 
Luther 2005 (Continued)

Random sequence generation (selection Low risk bias)

Allocation concealment (selection bias) Low risk
Quote: “A random number table was generated on an Excel spreadsheet by the trial's statistical advisor"

Quote: "Each time a patient agreed to take part in the study, a dental nurse who was not involved in the running of the study accessed the concealed table and crossed off the next number, informing the operator of the treatment to be used i.e. whether the patient had been allocated to the fluoride rinse or FGB group"

\begin{tabular}{|c|c|c|}
\hline Blinding - Patients \& Operators & High risk & $\begin{array}{l}\text { Not possible to blind participants or oper- } \\
\text { ators to allocated intervention }\end{array}$ \\
\hline Blinding - Outcome assessors & Low risk & $\begin{array}{l}\text { Quote: "Analysis was undertaken blind by } \\
\text { one operator, who was unaware of which } \\
\text { group the teeth being analysed came from" }\end{array}$ \\
\hline Incomplete outcome data addressed & High risk & $\begin{array}{l}14 \text { participants ( } 8 \text { F-releasing glass bead } \\
\text { and } 6 \text { rinse) dropped out - reasons not } \\
\text { given. Further } 19 \text { ( } 8 \text { F-releasing glass bead } \\
\text { and } 11 \text { rinse) excluded from analysis be- } \\
\text { cause of insufficient data, and reasons not } \\
\text { explained. } 47 \% \text { of randomised participants } \\
\text { not included in the analysis. High rate of } \\
\text { breakage of F-releasing glass beads. Sub- } \\
\text { stantial risk of bias due to attrition }\end{array}$ \\
\hline Free of selective reporting & Unclear risk & $\begin{array}{l}\text { Numbers of participants and teeth with } \\
\text { DWLs reported at the beginning and at the } \\
\text { end of the trial, but denominators were un- } \\
\text { clear. No indication of mean size of lesions } \\
\text { in each group. Salivary fluoride levels not } \\
\text { reported }\end{array}$ \\
\hline Free of other bias & Unclear risk & $\begin{array}{l}\text { Number of breakages of F-releasing glass } \\
\text { beads reported, but no indication of level } \\
\text { of compliance in fluoride rinse group. No } \\
\text { information on duration of trial and there- } \\
\text { fore duration of exposure to fluoride in each } \\
\text { group }\end{array}$ \\
\hline
\end{tabular}


Methods
Trial design: Parallel RCT

Unit of randomisation: Individuals

Location: Skelleftea \& Lycksele, Sweden

Number of centres: 2

Recruitment period: Not stated

Funding source: Grants from the County Council of Vasterbotten \& Swedish Dental Society, with varnishes supplied by Ivoclar Vivadent and brackets by $3 \mathrm{M}$ Unitek

Inclusion criteria: Children 12 to 15 years of age scheduled for maxillary treatment with fixed orthodontic appliances for an expected duration of at least 6 months

Exclusion criteria: None stated

Mean age at baseline, years: $14.3 \pm 1.6$

Number randomised: 273 (137 and 136)

Number evaluated: 257 (132 and 125)

Interventions

\section{Comparison: Fluoride varnish (Fluor Protector) versus placebo}

Group A ( $\mathrm{n}=137)$ : Fluor Protector $(0.1 \%$ F difluorosilane in polyurethane base) varnish applied after bonding and at each checkup (approximately every 6 weeks) until debonding Group B ( $\mathrm{n}=136)$ : Placebo varnish, identical in appearance to active, applied after bonding and at the end of each check-up (every 6 weeks) until debonding

In both groups, after removal of visible plaque with an explorer, 0.2 to $0.3 \mathrm{ml}$ varnish was applied around the bracket bases in a thin layer with a minibrush and was allowed to dry for 2 minutes. Participants were instructed to avoid all eating and drinking for 2 hours and to not brush teeth until the following day

Duration of treatment: Not given, but mean number of applications of varnish was 10 , and assuming they were seen every 6 weeks, the mean duration was 60 weeks or just over 1 year (which is quite short)

All children strongly advised to brush teeth with 1000 to $1500 \mathrm{ppm}$ fluoride toothpaste at least twice daily

Fluoride in piped drinking water in these communities was $<0.2 \mathrm{ppm}$
Before and after clinical photographs assessed for presence and severity of DWLs by 2 experienced and calibrated judges

Sample size calculation reported. Estimated requirement for 132 participants per group

\section{Support for judgement}

\section{Bias}

Authors' judgement

Random sequence generation (selection Low risk bias)
Quote (author): “The patients were assigned to one of the two groups on the basis of odd and even numbers from a dice" Comment: The corresponding author was asked how investigators obtained equal numbers in all groups but does not seem to have answered this 
Stecksén-Blicks 2007 (Continued)

\begin{tabular}{|c|c|c|}
\hline Allocation concealment (selection bias) & Low risk & $\begin{array}{l}\text { Quote (author): "The study was coordi- } \\
\text { nated from the Department of Paediatric } \\
\text { Dentistry and the randomization was per- } \\
\text { formed there by an independent technician } \\
\text { not involved in the clinical work and col- } \\
\text { lection of data" }\end{array}$ \\
\hline Blinding - Patients \& Operators & Low risk & $\begin{array}{l}\text { Quote (author): "The placebo varnish ap- } \\
\text { plied had an identical composition but } \\
\text { without fluoride. Both varnishes were un- } \\
\text { coloured and obtained from the producer } \\
\text { in identical bottles coded by colour. Nei- } \\
\text { ther clinicians nor patients knew whether } \\
\text { they were treated with fluoride or placebo } \\
\text { varnish" } \\
\text { Comment: The study was double-blind }\end{array}$ \\
\hline Blinding - Outcome assessors & Low risk & $\begin{array}{l}\text { Quote: The two "experienced and cali- } \\
\text { brated" judges who scored the photographs } \\
\text { for presence/absence and severity of DWLs } \\
\text { "were not involved in the treatment of the } \\
\text { patients and blinded for group assignment" }\end{array}$ \\
\hline Incomplete outcome data addressed & Low risk & $\begin{array}{l}\text { Comment: Flow diagram provided and } \\
\text { withdrawals and drop-outs reported }(5 / \\
137 \text { or } 4 \% \text { experimental; } 11 / 136 \text { or } 8 \% \\
\text { controls). Reasons given and similar in each } \\
\text { group. Unlikely to have introduced a bias }\end{array}$ \\
\hline Free of selective reporting & Low risk & $\begin{array}{l}\text { Planned outcome was white spot lesions at } \\
\text { debonding in each group. Reported as \% } \\
\text { prevalence with P value for difference be- } \\
\text { tween groups. No apparent evidence of se- } \\
\text { lective reporting }\end{array}$ \\
\hline Free of other bias & Low risk & No other sources of bias identified \\
\hline
\end{tabular}

Øgaard 2006

Methods

Trial design: 2-arm double-blind parallel-group RCT

Unit of randomisation: Individual

Location: Sweden

Number of centres: 2

Recruitment period: Starting orthodontic treatment in 1999

Funding source: The study was supported by GABA International, Basel, Switzerland

Fluorides for the prevention of early tooth decay (demineralised white lesions) during fixed brace treatment (Review) 


\section{Øgaard 2006 (Continued)}

\begin{tabular}{ll} 
Inclusion criteria: Participants were those starting orthodontic treatment in 1999 with \\
fixed appliances in both arches \\
Exclusion criteria: None stated \\
Age at baseline: Not stated \\
Number randomised: 115 \\
Number evaluated: 97 \\
\hline
\end{tabular}

Interventions

\section{Comparison: 2 different fluoride toothpastes and mouthrinses}

Group A $(n=50)$ : Participants were instructed to brush twice daily with toothpaste containing amine fluoride and stannous fluoride combination $\left(\mathrm{AmF} / \mathrm{SnF}_{2} 140 \mathrm{ppm}\right.$, $\mathrm{pH} 4.5$ ) and to rinse every evening after toothbrushing with a solution containing amine fluoride and stannous fluoride

Group B ( $\mathrm{n}=47)$ : Participants were instructed to brush twice daily with toothpaste containing neutral sodium fluoride ( $\mathrm{NaF} 1400 \mathrm{ppm}, \mathrm{pH}$ 6.7) and to rinse every evening after toothbrushing with a solution containing $\mathrm{NaF}$ (250 ppm, $\mathrm{pH}$ 6.3)

Duration of treatment: Fluoride treatments were continued for the whole duration of orthodontic treatment with fixed appliances

Outcomes

White spot lesion index, visible plaque index, gingival bleeding index, measured at baseline and at debonding

Notes Background exposure to fluoride: Not reported

Power calculation: Not reported

Risk of bias

Bias

Random sequence generation (selection Low risk bias)

Allocation concealment (selection bias) Unclear risk

Blinding - Outcome assessors

Low risk

Incomplete outcome data addressed Low risk

\section{Support for judgement}

Quote "allocated to two groups at bonding according to a randomized table"

Comment: Assumed this refers to random number table

Not described

Comment: Assumed not done

Double-blind. Quote: "Neither the subjects nor the research team were informed about which group each participant belonged to"

Double-blind. Quote: "Neither the subjects nor the research team were informed about which group each participant belonged to"
18 of the patients invited to participate were not included in the evaluation. Not 
Øgaard 2006 (Continued)

\begin{tabular}{l|l|l} 
& & $\begin{array}{l}\text { stated which groups they were from, but } \\
\text { it seems likely that number was similar } \\
\text { in each group. Reason given was moving } \\
\text { house }\end{array}$ \\
\hline $\begin{array}{l}\text { Free of selective reporting } \\
\text { Free of other bias }\end{array}$ & Low risk & Planned outcomes reported in full \\
\hline
\end{tabular}

$\mathrm{DWL}=$ demineralised white lesion; $\mathrm{F}$ = fluoride; $\mathrm{ppm}=$ parts per million; RCT = randomised controlled trial.

Characteristics of excluded studies [ordered by study ID]

\begin{tabular}{|c|c|}
\hline Study & Reason for exclusion \\
\hline Alexander 2000 & Clinical assessment carried out 1 month after debonding not immediately after \\
\hline Alwi 1994 & $\begin{array}{l}\text { Abstract only. Insufficient information to include in review. Contacted author. Unable to provide sufficient } \\
\text { data for analysis. No subsequent publication identified }\end{array}$ \\
\hline Banks 1997 & Split-mouth study \\
\hline Banks 2000 & CCT with alternate allocation to fluoride or non-fluoride elastomeric ligatures \\
\hline Blanco 1988 & $\begin{array}{l}\text { "Patients chosen at random" and divided into } 2 \text { groups. Report is unclear about the details of allocation } \\
\text { to each group, groups are unequal in size, no baseline characteristics, and no outcome data presented per } \\
\text { participant. Unable to contact authors and unable to include this study based on available information }\end{array}$ \\
\hline Boyd 1992 & Demineralisation assessed 3 months after debonding rather than immediately \\
\hline Boyd 1993 & Demineralisation assessed 3 months after debonding rather than immediately \\
\hline Boyles 2007 & Not RCT \\
\hline Buyukyilmaz 1994 & Split-mouth study \\
\hline Chung 1998 & Split-mouth study \\
\hline Czochrowska 1998 & Split-mouth study \\
\hline D’Agostino 1988 & Outcomes were DMFT and DMFS not demineralised white lesions \\
\hline Demito 2011 & Split-mouth study \\
\hline
\end{tabular}

Fluorides for the prevention of early tooth decay (demineralised white lesions) during fixed brace treatment (Review) 
(Continued)

\begin{tabular}{|c|c|}
\hline Dyer 1982 & Not RCT \\
\hline Dénes 1988 & Assessed DMFS not white spot lesions \\
\hline Dénes 1989 & Assessed DMFS not white spot lesions \\
\hline Dénes 1991 & Assessed DMFS not white spot lesions \\
\hline Farhadian 2008 & Not RCT \\
\hline Fricker 1985 & Not RCT \\
\hline Fricker 1987 & Not RCT \\
\hline Gaworski 1999 & Not RCT \\
\hline Geiger 1988 & Not RCT \\
\hline Geiger 1992 & Not RCT \\
\hline Gillgrass 2001 & Split-mouth study \\
\hline Gorton 2003 & Ex vivo study - outcomes measured on extracted teeth \\
\hline Hirschfield 1978 & Not RCT \\
\hline Leizer 2010 & $\begin{array}{l}\text { Appears to be allocation based on study number (odd or even) and teeth allocated alternately. CCT. No } \\
\text { reply to emails sent to contact author }\end{array}$ \\
\hline Maijer 1988 & Not RCT \\
\hline Marcusson 1997 & Split-mouth study \\
\hline Marini 1999 & $\begin{array}{l}\text { Duration of intervention } 12 \text { months but outcomes assessed at end of treatment period not at the end of } \\
\text { treatment with fixed orthodontic appliances }\end{array}$ \\
\hline Mattick 2001 & Split-mouth RCT \\
\hline Millett 1999 & Split-mouth study, allocation of each side to treatment by alternation. Not RCT \\
\hline Millett 2000 & Split-mouth study, allocation of each side to treatment by alternation.Not RCT \\
\hline Mitchell 1992 & Split-mouth study, no random allocation. Author contacted \\
\hline Neumann 1976 & Abstract only. Insufficient data, no subsequent publication identified \\
\hline O’Reilly 1987 & Ex vivo study - outcomes measured on extracted teeth \\
\hline
\end{tabular}

Copyright $\odot 2013$ The Cochrane Collaboration. Published by John Wiley \& Sons, Ltd. 
(Continued)

\begin{tabular}{|c|c|}
\hline Pascotto 2004 & Ex vivo study - outcomes measured on extracted teeth \\
\hline Robertson 2011 & $\begin{array}{l}\text { Duration of intervention } 12 \text { months but outcomes assessed at end of treatment period not at the end of } \\
\text { treatment with fixed orthodontic appliances }\end{array}$ \\
\hline Salzmann 1976 & Abstract only. No subsequent publication identified \\
\hline Shan 2008 & Split-mouth study \\
\hline Shannon 1978 & Allocation method not stated. Unable to contact the authors \\
\hline Shannon 1979 & Allocation method not stated. Unable to contact the authors \\
\hline Sköld-Larsson 2013 & $\begin{array}{l}\text { Intervention period was short ( } 12 \text { weeks) and assessments were not undertaken at the start and end of } \\
\text { orthodontic treatment }\end{array}$ \\
\hline Sonis 1989 & Not RCT \\
\hline Trimpeneers 1996 & $\begin{array}{l}\text { Split-mouth study. All participants had the same product used in the same quadrants. Not RCT.Contacted } \\
\text { author (LR Dermaut). Unable to provide further data for statistical analysis }\end{array}$ \\
\hline Turner 1993 & Split-mouth study \\
\hline Twetman 1997 & Split-mouth study \\
\hline Ullsfoss 1994 & $\begin{array}{l}\text { Both groups had fluoride mouthrinse. The experimental group had in addition an antimicrobial } \\
\text { mouthrinse, therefore the study looks at the efficacy of the antimicrobial mouthrinse rather than the flu- } \\
\text { oride mouthrinse }\end{array}$ \\
\hline Underwood 1989 & Random allocation not mentioned. Brackets on alternate teeth bonded with each adhesive. Not RCT \\
\hline van der Linden 1998 & Split-mouth study \\
\hline Vivaldi-Rodrigues 2006 & Split-mouth study \\
\hline Wenderoth 1999 & Not RCT \\
\hline Øgaard 1986 & Ex vivo study - outcomes measured on extracted teeth \\
\hline Øgaard 1992 & Random allocation to treatment not mentioned. Author contacted \\
\hline Øgaard 1996 & Not RCT. Author contacted \\
\hline Øgaard 1997 & $\begin{array}{l}\text { Effect of fluoride confounded by co-intervention. Both groups had fluoride varnish. The experimental } \\
\text { group had in addition an antimicrobial varnish therefore the study looks at the efficacy of the antimicrobial } \\
\text { varnish rather than the fluoride varnish }\end{array}$ \\
\hline
\end{tabular}

Fluorides for the prevention of early tooth decay (demineralised white lesions) during fixed brace treatment (Review) 
(Continued)

Øgaard 2001

Effect of fluoride confounded by co-intervention. 2 randomised groups and 1 non-randomised control group. Both randomised groups received fluoride varnish every 12 weeks, fluoride exposure was not different between the 2 randomised groups

CCT = controlled clinical trial; DMFS/DMFT = decayed, missing and filled surfaces/teeth.

\section{Characteristics of ongoing studies [ordered by study ID]}

\section{NCT00268138}

\begin{tabular}{ll} 
Trial name or title & $\begin{array}{l}\text { Phase } 4 \text { study on prevention of incipient carious lesions (white spot lesions) in patients with fixed orthodontic } \\
\text { appliances following the application of Elmex gel }\end{array}$ \\
\hline Methods & Parallel-group, double-blind RCT \\
\hline Participants & 314 healthy participants between 10 and 60 years of age, undergoing orthodontic treatment \\
\hline Interventions & $\begin{array}{l}\text { Toothbrushing with Elmex gel or placebo product once weekly during the entire study (12 to } 30 \text { months) } \\
\text { plus tray application of test or control product } 4 \text { times per year }\end{array}$ \\
\hline Outcomes & Visually detected white spot lesions \\
\hline Starting date & April 2006 \\
\hline Contact information & $\begin{array}{l}\text { Principal Investigators Dr Meir Radlich (mredlich@zahav.net.il) and Prof Paul George Jost-Brinkman (paul- } \\
\text { g.jost-brinkmann@ charite.de) }\end{array}$ \\
\hline Notes & $\begin{array}{l}\text { Email sent to Jost-Brinkmann to request results } 19 / 7 / 2012 . \text { Email reply } 19 / 7 / 2012 \text { stating that last participant } \\
\text { now finished and data analysis about to start }\end{array}$ \\
\hline
\end{tabular}

\section{NCT01768390}

\begin{tabular}{|c|c|}
\hline Trial name or title & $\begin{array}{l}\text { Caries-preventive effectiveness of a dentifrice containing } 5000 \mathrm{ppm} \text { fluoride - a randomised controlled trial } \\
\text { in adolescents with fixed orthodontic appliances }\end{array}$ \\
\hline Methods & Parallel-group single-blind RCT \\
\hline Participants & 420 healthy participants 11 to 16 years old, undergoing orthodontic treatment \\
\hline Interventions & High-dose $(5000 \mathrm{ppm})$ fluoride toothpaste versus usual-dose (1450 ppm) fluoride toothpaste \\
\hline Outcomes & Incidence and severity of white spot lesions over the duration of orthodontic treatment (18 to 24 months) \\
\hline Starting date & January 2008. Data collection expected to be complete July 2012 \\
\hline
\end{tabular}

Copyright @ 2013 The Cochrane Collaboration. Published by John Wiley \& Sons, Ltd. 


\section{NCT01768390 (Continued)}

\section{Contact information Professor SHA Twetman, University of Copenhagen (stw@odont.ku.dk )}

Email sent to Prof Twetman 24 June 2013. Reply 25 June 2013: "The study is completed and the manuscript
was submitted for publication about one month ago. We have not yet received any response from the journal
but if we are lucky, it will appear "on line“ later this year." Abstract presented at European Orthodontic
Society meeting, Reykjvik, Iceland, June 2013

\section{NCT01925924}

Trial name or title Resin-modified glass ionomer or composite for orthodontic bonding? A multicentre, randomised, singleblinded clinical trial

\begin{tabular}{ll}
\hline Methods & A multicentre randomised single-blinded controlled clinical trial with 2 parallel groups \\
\hline Participants & $\begin{array}{l}\text { 206 orthodontic patients requiring upper and/or lower preadjusted edgewise fixed appliance therapy, 11 years } \\
\text { of age or older }\end{array}$ \\
\hline Interventions & $\begin{array}{l}\text { Brackets will be bonded to all teeth in front of the first permanent molars with either a resin-modified glass } \\
\text { ionomer cement (Fuji Ortho LC) or a light cured composite control (Transbond) }\end{array}$ \\
\hline Outcomes & $\begin{array}{l}\text { Primary: Incidence and severity of demineralisation at the end of treatment. Secondary: Incidence of first } \\
\text { time bond failures }\end{array}$ \\
\hline Starting date & February 2009 \\
\hline Contact information & Dr Philip Benson, University of Sheffield (p.benson@sheffield.ac.uk) \\
\hline Notes & \\
\hline
\end{tabular}

ppm = parts per million; RCT $=$ randomised controlled trial 
DATA AND ANALYSES

Comparison 1. Fluoride varnish versus placebo varnish

\begin{tabular}{|c|c|c|c|c|}
\hline Outcome or subgroup title & $\begin{array}{l}\text { No. of } \\
\text { studies }\end{array}$ & $\begin{array}{c}\text { No. of } \\
\text { participants }\end{array}$ & Statistical method & Effect size \\
\hline $\begin{array}{l}1 \text { Number of participants with } \\
\text { new DWLs }\end{array}$ & 1 & & Risk Ratio (M-H, Fixed, 95\% CI) & Subtotals only \\
\hline
\end{tabular}

Comparison 2. Amine fluoride/stannous fluoride toothpaste/mouthrinse combination versus sodium fluoride toothpaste/mouthrinse combination

\begin{tabular}{|c|c|c|c|c|}
\hline Outcome or subgroup title & $\begin{array}{l}\text { No. of } \\
\text { studies }\end{array}$ & $\begin{array}{c}\text { No. of } \\
\text { participants }\end{array}$ & Statistical method & Effect size \\
\hline 1 White spot index & 1 & & Mean Difference (IV, Fixed, 95\% CI) & Totals not selected \\
\hline 2 Visible plaque index & 1 & & Mean Difference (IV, Fixed, 95\% CI) & Totals not selected \\
\hline 3 Gingival bleeding index & 1 & & Mean Difference (IV, Fixed, 95\% CI) & Totals not selected \\
\hline
\end{tabular}

Comparison 3. Intraoral fluoride-releasing glass bead device versus mouthrinse-only control

\begin{tabular}{|c|c|c|c|c|}
\hline Outcome or subgroup title & $\begin{array}{l}\text { No. of } \\
\text { studies }\end{array}$ & $\begin{array}{c}\text { No. of } \\
\text { participants }\end{array}$ & Statistical method & Effect size \\
\hline $\begin{array}{l}1 \text { Number of participants with } \\
\text { new DWLs }\end{array}$ & 1 & & Risk Ratio (M-H, Fixed, 95\% CI) & Totals not selected \\
\hline $\begin{array}{l}1.1 \text { Fluoride-releasing } \\
\text { intraoral device versus fluoride } \\
\text { mouthrinse }\end{array}$ & 1 & & Risk Ratio (M-H, Fixed, 95\% CI) & $0.0[0.0,0.0]$ \\
\hline
\end{tabular}


Analysis I.I. Comparison I Fluoride varnish versus placebo varnish, Outcome I Number of participants with new DWLs.

Review: Fluorides for the prevention of early tooth decay (demineralised white lesions) during fixed brace treatment

Comparison: I Fluoride varnish versus placebo varnish

Outcome: I Number of participants with new DWLs

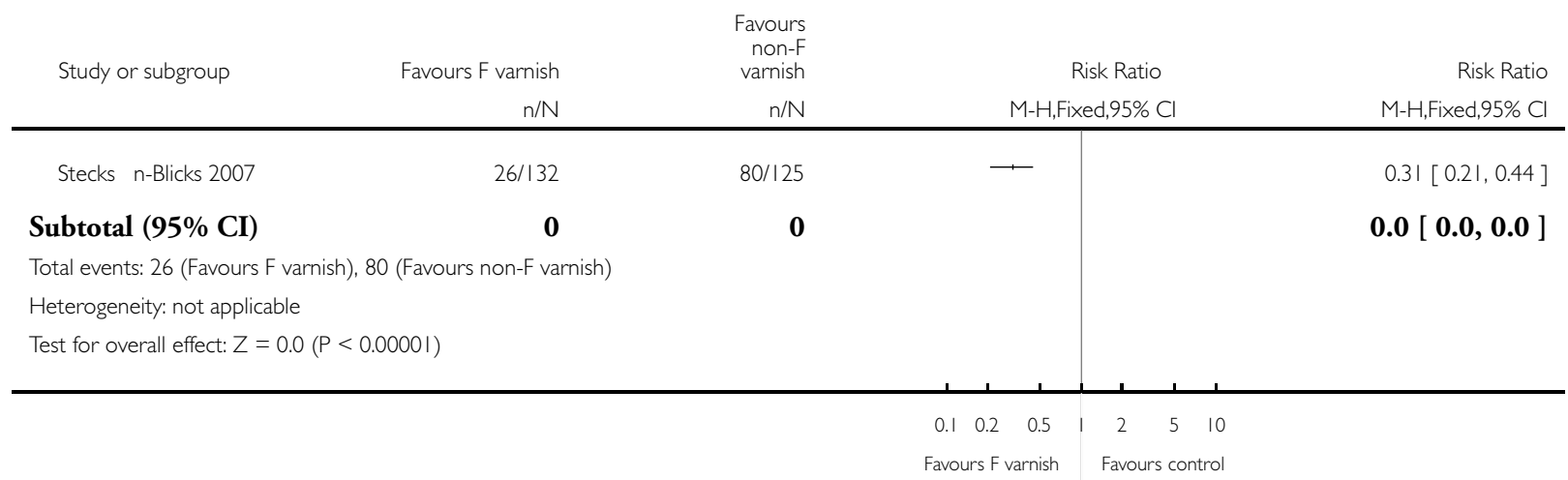

Analysis 2.1. Comparison 2 Amine fluoride/stannous fluoride toothpaste/mouthrinse combination versus sodium fluoride toothpaste/mouthrinse combination, Outcome I White spot index.

Review: Fluorides for the prevention of early tooth decay (demineralised white lesions) during fixed brace treatment

Comparison: 2 Amine fluoride/stannous fluoride toothpaste/mouthrinse combination versus sodium fluoride toothpaste/mouthrinse combination

Outcome: I White spot index

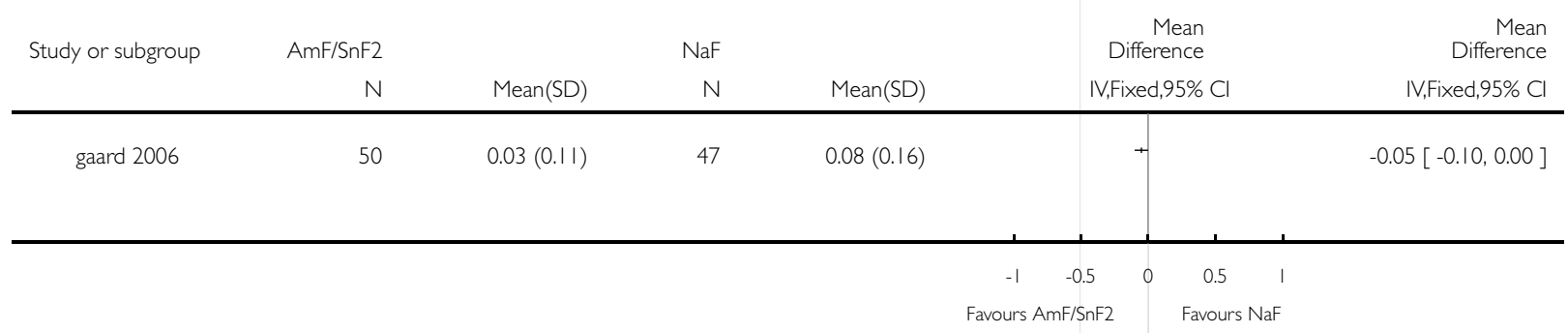

Fluorides for the prevention of early tooth decay (demineralised white lesions) during fixed brace treatment (Review) 
Analysis 2.2. Comparison 2 Amine fluoride/stannous fluoride toothpaste/mouthrinse combination versus sodium fluoride toothpaste/mouthrinse combination, Outcome 2 Visible plaque index.

Review: Fluorides for the prevention of early tooth decay (demineralised white lesions) during fixed brace treatment

Comparison: 2 Amine fluoride/stannous fluoride toothpaste/mouthrinse combination versus sodium fluoride toothpaste/mouthrinse combination

Outcome: 2 Visible plaque index

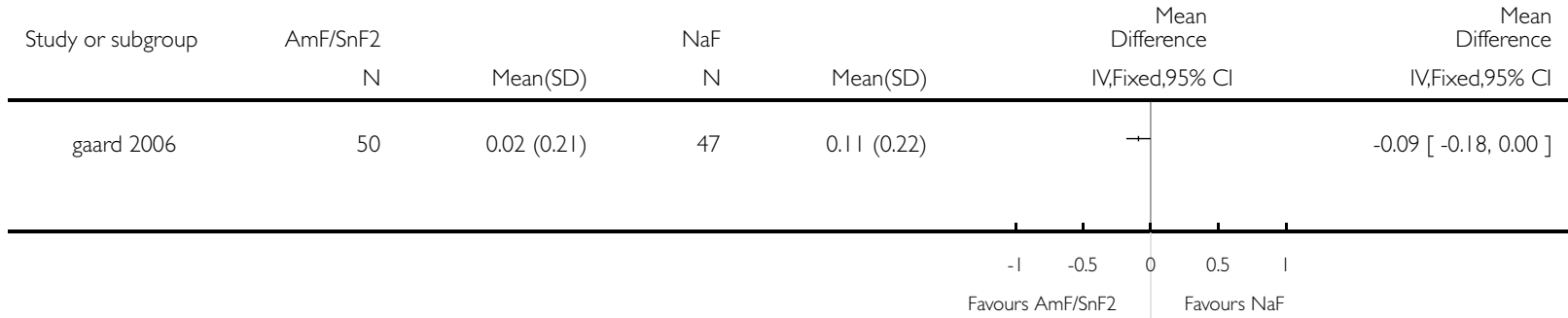

Analysis 2.3. Comparison 2 Amine fluoride/stannous fluoride toothpaste/mouthrinse combination versus sodium fluoride toothpaste/mouthrinse combination, Outcome 3 Gingival bleeding index.

Review: Fluorides for the prevention of early tooth decay (demineralised white lesions) during fixed brace treatment

Comparison: 2 Amine fluoride/stannous fluoride toothpaste/mouthrinse combination versus sodium fluoride toothpaste/mouthrinse combination

Outcome: 3 Gingival bleeding index

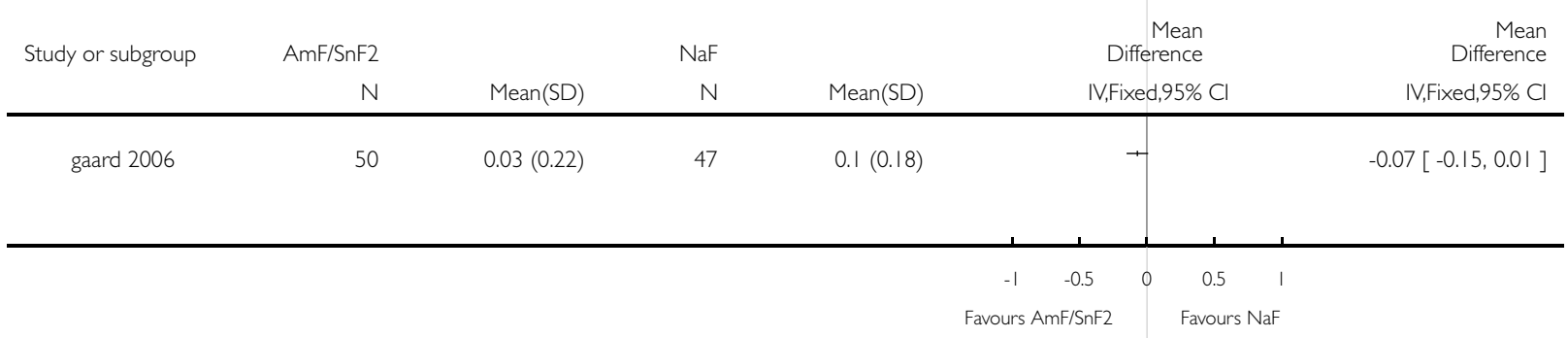


Analysis 3.I. Comparison 3 Intraoral fluoride-releasing glass bead device versus mouthrinse-only control, Outcome I Number of participants with new DWLs.

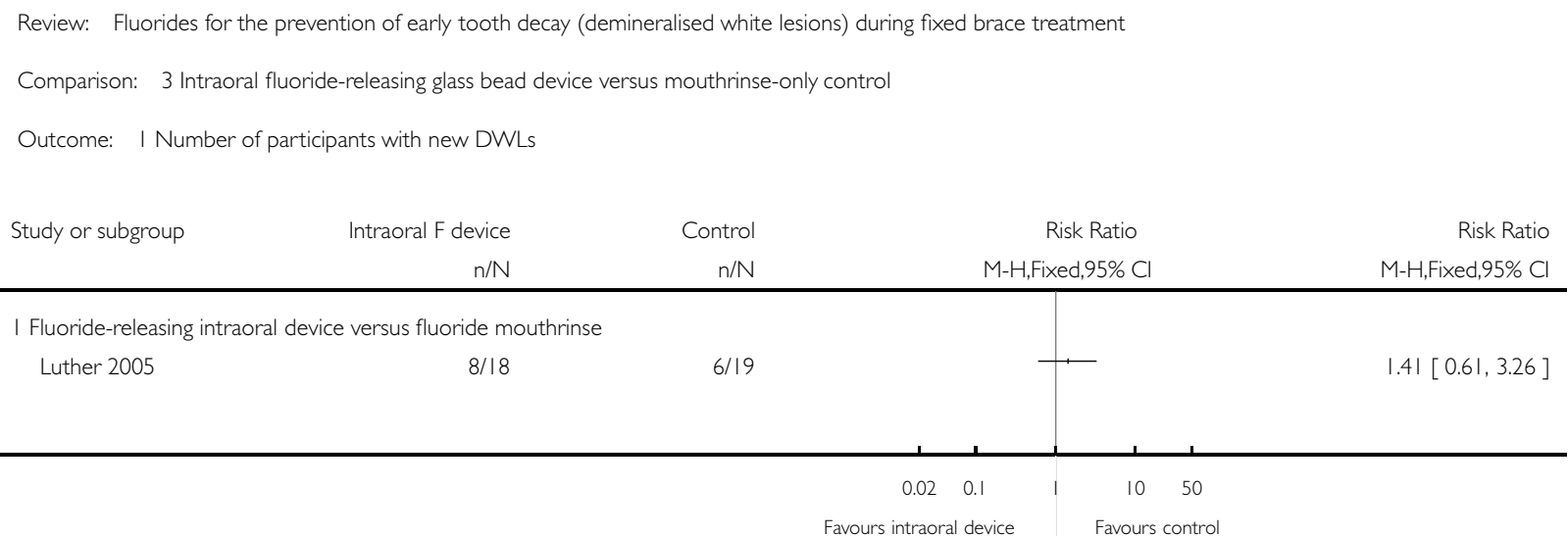

\section{A P P E N D I C E S}

\section{Appendix I. Cochrane Oral Health Group's Trials Register search strategy}

(orthodontic* AND (cariostatic* OR fluoride* OR naf OR "glass ionomer*” OR "cermet cement*” OR compomer* OR "composite resin*”) AND (“dental enamel solubility” OR caries OR “dental fissures” OR demineriali* OR reminerali* OR decalcifi* OR “white

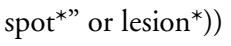

\section{Appendix 2. Cochrane Central Register of Controlled Trials (CENTRAL) search strategy}

\#1 MeSH descriptor Orthodontics explode all trees

$\# 2$ orthodontic*

\#3 (\#1 OR \#2)

\#4 MeSH descriptor Sodium Fluoride explode all trees

\#5 MeSH descriptor Fluorides, Topical explode all trees

\#6 fluoride*

\#7 topical next fluoride*

$\# 8 \mathrm{NaF}$

\#9 MeSH descriptor Glass Ionomer Cements, this term only

\#10 glass next ionomer*

\#11 (\#4 OR \#5 OR \#6 OR \#7 OR \#8 OR \#9 OR \#10)

\#12 MeSH descriptor Dental Enamel Solubility explode all trees

\#13 MeSH descriptor Tooth Demineralization explode all trees

\#14 reminerali* or deminerali* or decalcif*

$\# 15$ white next spot*

\#16 (\#12 OR \#13 OR \#14 OR \#15)

\#17 (\#3 AND \#11 AND \#16)

Fluorides for the prevention of early tooth decay (demineralised white lesions) during fixed brace treatment (Review)

Copyright @ 2013 The Cochrane Collaboration. Published by John Wiley \& Sons, Ltd. 


\title{
Appendix 3. MEDLINE (OVID) search strategy
}

\author{
1. $\exp$ ORTHODONTICS/ \\ 2. orthodontic\$.mp. \\ 3. 1 or 2 \\ 4. $\exp$ SODIUM FLUORIDE/ \\ 5. exp FLUORIDES TOPICAL/ \\ 6. fluoride\$.mp. \\ 7. NaF.ti,ab. \\ 8. Glass Ionomer Cements/ \\ 9. (glass adj ionomer\$).mp. \\ 10. or/4-9 \\ 11. exp DENTAL ENAMEL SOLUBILITY/ \\ 12. TOOTH DEMINERALIZATION/ \\ 13. (reminerali\$ or deminerali $\$$ or decalcif\$).mp. \\ 14. ((white adj spot\$) or lesion\$).mp. \\ 15. 11 or 12 or 13 or 14 \\ 16. 3 and 10 and 15
}

The above subject search was linked to the Cochrane Highly Sensitive Search Strategy (CHSSS) for identifying randomised trials in MEDLINE: sensitivity maximising version (2008 revision), as referenced in Chapter 6.4.11.1 and detailed in Box 6.4.c of theCochrane Handbook for Systematic Reviews of Interventions, Version 5.1.0 [updated March 2011].

1. randomized controlled trial.pt.

2. controlled clinical trial.pt.

3. randomized.ab.

4. placebo.ab.

5. drug therapy.fs.

6. randomly.ab.

7. trial.ab.

8. groups.ab.

9. or/1-8

10. exp animals/ not humans.sh.

11. 9 not 10

\section{Appendix 4. EMBASE (OVID) search strategy}

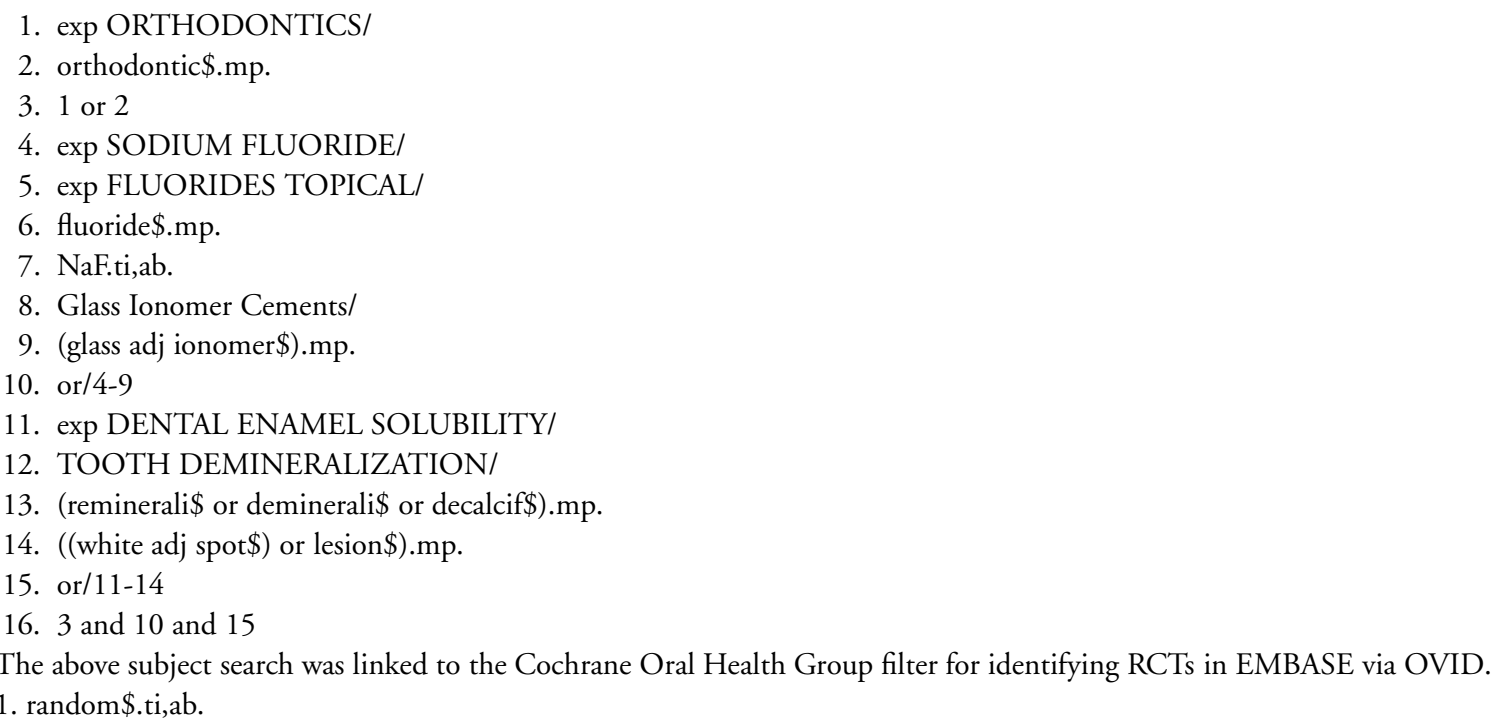

Fluorides for the prevention of early tooth decay (demineralised white lesions) during fixed brace treatment (Review)

Copyright $\odot 2013$ The Cochrane Collaboration. Published by John Wiley \& Sons, Ltd. 
2. factorial\$.ti,ab.

3. (crossover $\$$ or cross over $\$$ or cross-over $\$$ ).ti,ab.

4. placebo\$.ti,ab.

5. (doubl\$ adj blind\$).ti,ab.

6. (singl\$ adj blind\$).ti,ab.

7. assign\$.ti,ab.

8. allocat\$.ti,ab.

9. volunteer\$.ti,ab.

10. CROSSOVER PROCEDURE.sh.

11. DOUBLE-BLIND PROCEDURE.sh.

12. RANDOMIZED CONTROLLED TRIAL.sh.

13. SINGLE BLIND PROCEDURE.sh.

14. or/1-13

15. ANIMAL/ or NONHUMAN/ or ANIMAL EXPERIMENT/

16. HUMAN/

17. 16 and 15

18. 15 not 17

19. 14 not 18

\section{Appendix 5. US National Institutes of Health Trials Register search strategy}

We used the search terms "orthodontic* and fluoride" to search this database on 25 June 2013 (http://clinicaltrials.gov).

\section{WHAT'S NEW}

Last assessed as up-to-date: 31 January 2013.

\begin{tabular}{l|l|l}
\hline Date & Event & Description \\
\hline 3 December 2013 & New citation required and conclusions have changed & $\begin{array}{l}\text { Changes to inclusion criteria, 3 parallel-group studies } \\
\text { added and 14 previously included studies now excluded. } \\
\text { New methods implemented and Summary of findings } \\
\text { table added. Conclusions changed }\end{array}$ \\
\hline 1 May 2013 & New search has been performed & Searches updated to January 2013. \\
\hline
\end{tabular}

\section{CONTRIBUTIONS OF AUTHORS}

Philip Benson wrote the protocol and co-ordinated the review. Philip Benson, Fiona Dyer, Peter Germain, Declan Millett and Nicola Parkin independently and in duplicate assessed the eligibility of trials, extracted data and assessed the quality of the trials. Philip Benson contacted authors, entered the data, carried out the statistical analysis (with help from Helen Worthington) and wrote the review. Declan Millett proofread the review.

For the 2013 update of this review, Philip Benson and Susan Furness contacted authors, assessed risk of bias, extracted and entered data, carried out the statistical analysis (with help from Helen Worthington) and wrote the text of the review.

Fluorides for the prevention of early tooth decay (demineralised white lesions) during fixed brace treatment (Review) 


\section{DECLARATIONSOF INTEREST}

No interests to declare.

\section{SOURCES OF SUPPORT}

\section{Internal sources}

- School of Clinical Dentistry, University of Sheffield, UK.

- Dental School, University College Cork, Ireland.

- School of Dentistry, The University of Manchester, UK.

- MAHSC, UK.

The Cochrane Oral Health Group is supported by the Manchester Academic Health Sciences Centre (MAHSC) and the NIHR Manchester Biomedical Research Centre.

\section{External sources}

- Cochrane Oral Health Group Global Alliance, UK.

All reviews in the Cochrane Oral Health Group are supported by Global Alliance member organisations (British Association of Oral Surgeons, UK; British Orthodontic Society, UK; British Society of Paediatric Dentistry, UK; British Society of Periodontology, UK; Canadian Dental Hygienists Association, Canada; National Center for Dental Hygiene Research \& Practice, USA; Mayo Clinic, USA; New York University College of Dentistry, USA; and Royal College of Surgeons of Edinburgh, UK) providing funding for the editorial process (http://ohg.cochrane.org/).

- National Institute for Health Research (NIHR), UK.

CRG funding acknowledgement:

The NIHR is the largest single funder of the Cochrane Oral Health Group.

Disclaimer:

The views and opinions expressed therein are those of the authors and do not necessarily reflect those of the NIHR, NHS or the Department of Health.

\section{DIFFERENCES BETWEEN PROTOCOLANDREVIEW}

In the 2013 update of this review, controlled clinical trials (quasi-randomised) were excluded.

A point of clarification was added to the inclusion criteria for this review. For a randomised controlled trial to be included, demineralised white lesions (DWLs) must be assessed on teeth remaining in the mouth. Studies that evaluated demineralisation of extracted teeth were excluded from the 2013 update of this review because they measured the effects of short-term exposure to fluoride (four to six weeks between application and extraction of the teeth). Furthermore, it was decided that evaluation of demineralisation must take place at the end of treatment with fixed orthodontic appliances (debonding).

As stated in the Discussion of the previous version of this review, the use of a split-mouth study design to evaluate these interventions is potentially inappropriate. It is unlikely that the fluoride released will be confined to only the quadrants or the specific teeth in which the experimental material has been placed, and some 'contamination' of teeth in the control quadrants is inevitable. This will reduce the difference in outcome between experimental and control teeth and will reduce the power of the trial to find a difference. Indeed splitmouth studies included in the previous version of this review found no difference between teeth with fluoridated bracket adhesives and those without, supporting the view that this design is inappropriate for evaluating topical fluorides. Split-mouth studies were excluded from the 2013 update of this review, and the Methods sections of this review was amended to remove methods that were used to deal with split-mouth studies.

Fluorides for the prevention of early tooth decay (demineralised white lesions) during fixed brace treatment (Review) 


\section{INDEX TERMS}

\section{Medical Subject Headings (MeSH)}

Dental Caries [* prevention \& control]; Fluorides [ ${ }^{*}$ therapeutic use]; Mouthwashes [ ${ }^{*}$ therapeutic use]; Orthodontic Brackets [*adverse effects]; Randomized Controlled Trials as Topic

\section{MeSH check words}

Humans 